Provided for non-commercial research and education use. Not for reproduction, distribution or commercial use.

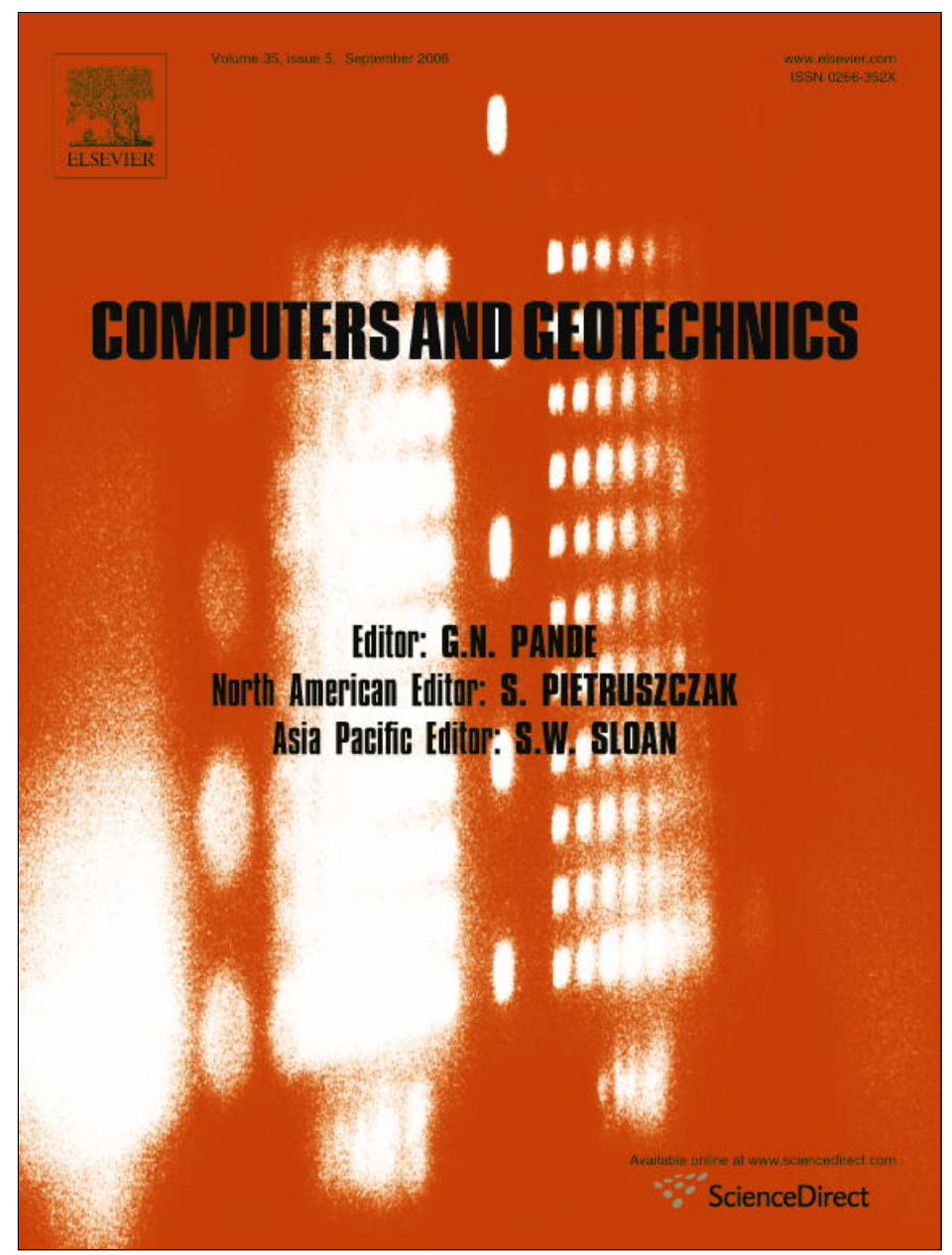

This article appeared in a journal published by Elsevier. The attached copy is furnished to the author for internal non-commercial research and education use, including for instruction at the authors institution and sharing with colleagues.

Other uses, including reproduction and distribution, or selling or licensing copies, or posting to personal, institutional or third party websites are prohibited.

In most cases authors are permitted to post their version of the article (e.g. in Word or Tex form) to their personal website or institutional repository. Authors requiring further information regarding Elsevier's archiving and manuscript policies are encouraged to visit:

http://www.elsevier.com/copyright 


\title{
Numerical simulation of the non-isothermal mechanical behaviour of soils
}

\author{
L. Lalouia ${ }^{\text {a,* }}$, C. Cekerevac ${ }^{\text {b, } 1}$ \\ ${ }^{a}$ Ecole Polytechnique Fédérale de Lausanne (EPFL), Soil Mechanics Laboratory, Station 18, CH-1015 Lausanne, Switzerland \\ ${ }^{\mathrm{b}}$ Stucky Ltd., Rue du Lac 33, 1020 Renens, Switzerland
}

Received 2 February 2007; received in revised form 22 November 2007; accepted 29 November 2007

Available online 15 January 2008

\begin{abstract}
Research interest in the thermo-mechanical behaviour of soils is growing as a result of an increasing number of geomechanical problems involving thermal effects. This paper concerns the constitutive modelling of non-isothermal mechanical behaviour of clayey soils. An elastoplastic model is extended to non-isothermal conditions to account for non-linearities and hardening that occurs as a result of heating of soils. This constitutive model includes evolution of the yield limit with temperature through a dependency law for pre-consolidation pressure with respect to heating. Numerical simulations support the theoretical aspects of the paper by demonstrating the ability of this non-isothermal constitutive law to represent the complete behaviour of clayey soils at different temperatures and stress states. Therefore, the model can be used for quantitative predictions of thermo-mechanical behaviour of clayey soils.

(C) 2007 Elsevier Ltd. All rights reserved.
\end{abstract}

Keywords: Non-isothermal constitutive modelling; Elasto-thermoplasticity; Thermal effects; Numerical simulation; Coupled multi-mechanisms plasticity

\section{Introduction}

In recent years, non-isothermal geomechanical problems have increased as a result of the demand for innovative applications, including reservoir engineering, high-level nuclear waste disposal, heat storage, geothermal structures, and others related to the seasonal and daily cyclical changes of temperature such as road subgrades and furnace foundations. Due to the importance of such applications, the thermo-mechanical behaviour of soils has become one of the major issues in modern soil mechanics.

Constitutive models for the simulation of the heat effect on the mechanical behaviour of soils exist in the literature. Hueckel and Borsetto [9] presented the first constitutive thermo-mechanical model for soils, including thermo-plasticity. Modaressi and Laloui [18], Cui et al. [6] and Graham

\footnotetext{
* Corresponding author. Tel.: +41 21693 2314; fax: +41 216934153 .

E-mail address: lyesse.laloui@epfl.ch (L. Laloui).

${ }^{1}$ Tel.: +4121637 1513; fax: +41216371508.
}

et al. [8] are among the other most significant contributions to this field.

This paper addresses the thermo-mechanical constitutive modelling issue (stress-strain-temperature relations) and presents an elasto-plastic model for the non-isothermal behaviour of cohesive soils. After a presentation of the mathematical formulation of the model supported by experimental data, some selected comparisons between numerical simulations and experimental results for different combinations of thermo-mechanical loading paths are presented. Here, we aim to demonstrate that the model represents the complete behaviour of clayey soils at different temperatures and stress states. It can then be used for quantitative predictions of the thermo-mechanical behaviour of clayey soils.

The presented model is an improved version of the rateindependent (elasto-thermoplastic) version of the LTVP elasto-thermoviscoplastic constitutive model proposed by Modaressi and Laloui [18]. The improved aspects concerns the dependency law for pre-consolidation pressure with respect to temperature and the support of some assumptions 
based on newly available comprehensive experimental results [5], which include (i) triaxial shear tests at ambient and high temperatures for different initial overconsolidation ratios, (ii) consolidation tests at different temperatures and (iii) drained thermal heating tests for different initial overconsolidation ratios. These results will not be discussed here but will be used to justify some assumptions made during the initial formulation of the model. Readers interested in these experimental data are referred to the original publication.

Here, the considered temperature range is from 4 to $95^{\circ} \mathrm{C}$, which corresponds to that principally encountered in geo-environmental applications (without freezing or boiling the pore water).

\section{Elasto-plasticity under non-isothermal conditions}

Conventional plasticity is adopted to develop the thermo-mechanical formulation. Due to strain history dependence, the formulation is given in the incremental form. In the presence of a temperature field, the elastoplasticity principle (concept of a loading surface $f$ in stress space, which limits the region of elastic deformation), allows the total strain rate, $\dot{\boldsymbol{\varepsilon}}$, to be split into reversible and irreversible parts:

$\dot{\boldsymbol{\varepsilon}}=\dot{\boldsymbol{\varepsilon}}^{\mathrm{Te}}+\dot{\boldsymbol{\varepsilon}}^{\mathrm{Tp}}$

with $\dot{\boldsymbol{\varepsilon}}^{\mathrm{Te}}$ being the reversible non-linear thermo-elastic strain rate resulting from the superposition of the mechanical elastic strain rate under isothermal conditions, $\dot{\boldsymbol{\varepsilon}}^{\mathrm{e}}$, and the reversible thermal strain rate, $\dot{\boldsymbol{\varepsilon}}^{\mathrm{T}}$ :

$\dot{\boldsymbol{\varepsilon}}^{\mathrm{Te}}=\dot{\boldsymbol{\varepsilon}}^{\mathrm{e}}+\frac{\beta_{\mathrm{s}}^{\prime}}{3} \dot{T} \boldsymbol{I}$

where $\dot{T}$ is the temperature rate, $\beta_{\mathrm{s}}^{\prime}$ the volumetric dilatation coefficient and $\boldsymbol{I}$ the second-order unit tensor. Temperature changes do not affect the elastic deviatoric strain.

The constitutive relation is introduced as

$\dot{\boldsymbol{\varepsilon}}^{\mathrm{e}}=\mathbf{D}^{-1} \cdot \dot{\boldsymbol{\sigma}}^{\prime}$

with $\mathbf{D}\left(\boldsymbol{\sigma}^{\prime}, T\right)$ being the elastic tangent stiffness tensor that depends on temperature and effective stress $\boldsymbol{\sigma}^{\prime}$. The thermo-plastic strain rate, $\dot{\boldsymbol{\varepsilon}}^{\mathrm{Tp}}$, is expressed using the normality rule as (in the general form)

$\dot{\boldsymbol{\varepsilon}}^{\mathrm{Tp}}=\dot{\lambda} \partial_{\sigma^{\prime}} Q$,

where $\dot{\lambda}\left(\boldsymbol{\sigma}^{\prime}, \boldsymbol{\alpha}, T\right) \geqslant 0$ is the plastic multiplier and $Q\left(\boldsymbol{\sigma}^{\prime}, \boldsymbol{\alpha}, T\right)$ represents the plastic potential function $\left(\partial_{\boldsymbol{\sigma}^{\prime}} Q\right.$ gives the direction of the plastic strain increment). $\alpha$ represents the internal (mechanical) variables that modify the yield surface $f\left(\boldsymbol{\sigma}^{\prime}, \boldsymbol{\alpha}, T\right)$. With respect to isothermal plasticity, the loading surface also depends on temperature, i.e., a relation of the form $f\left(\boldsymbol{\sigma}^{\prime}, \boldsymbol{\alpha}, T\right)=0$ defines it. In view of the yield law (4), the relationship (3) can be re-written as follows:

$\dot{\boldsymbol{\sigma}}^{\prime}=\mathbf{D} \cdot\left(\dot{\boldsymbol{\varepsilon}}-\dot{\lambda} \partial_{\sigma^{\prime}} Q-\frac{\beta_{\mathrm{s}}^{\prime}}{3} \dot{T} \boldsymbol{I}\right)$.
Changes in the material state with plastic deformation are possible only if they satisfy the following consistency equation $[20,9]$ :

$\mathrm{d} f=\partial_{\boldsymbol{\sigma}^{\prime}} f \cdot \dot{\boldsymbol{\sigma}}^{\prime}+\partial_{\alpha} f \cdot \dot{\boldsymbol{\alpha}}+\partial_{\mathrm{T}} f \cdot \dot{T}=0$.

Hence, it is possible to deduce the plastic multiplier by substituting Eq. (5) into Eq. (6).

\section{Non-isothermal constitutive model}

In this study, the basic isothermal framework is the multi-mechanism elastoplastic model developed by Hujeux [10]. This model is a generalisation of the critical state concept of Roscoe et al. [22] to a multi-mechanism elasto-plasticity, following the Koiter-Mandel theory [17]. The perfect plasticity limit criterion of the Hujeux model is analogous to that of the Mohr-Coulomb model and its yield function is similar to that of the original Cam-clay. The stress space is considered in three orthogonal planes in which a plane plastic strain hypothesis is adopted. The irreversible phenomenon is represented by four coupled elementary elasto-plastic mechanisms: three deviatoric (in three orthogonal planes) and one isotropic. Each mechanism is characterised by its own hardening parameters and all four mechanisms are coupled by the volumetric plastic strain, $\varepsilon_{\mathrm{v}}^{\mathrm{Tp}}=\sum_{k=1}^{4} \varepsilon_{\mathrm{vk}}^{\mathrm{Tp}}$, where $k$ is the considered mechanism. Readers interested in the details of this isothermal framework are referred to the original publications $[10,18]$. The necessary equations will be introduced in the following sections.

\subsection{Thermo-elastic component}

The thermo-elastic strain rate is expressed as

$\dot{\varepsilon}_{\mathrm{v}}^{\mathrm{Te}}=\frac{\dot{p}^{\prime}}{K}+\beta_{\mathrm{s}}^{\prime} \dot{T}, \quad \dot{\boldsymbol{\varepsilon}}_{\mathrm{d}}^{\mathrm{e}}=\frac{\dot{\boldsymbol{\sigma}}_{\mathrm{d}}}{2 G}$,

where $\dot{\varepsilon}_{\mathrm{v}}^{\mathrm{Te}}$ is the volumetric strain rate $\left(\dot{\varepsilon}_{\mathrm{v}}^{\mathrm{Te}}=\operatorname{tr}\left(\dot{\boldsymbol{\varepsilon}}^{\mathrm{Te}}\right)\right)$ and $\dot{\boldsymbol{\varepsilon}}_{\mathrm{d}}^{\mathrm{e}}$ the deviatoric strain rate $\left(\dot{\boldsymbol{\varepsilon}}_{\mathrm{d}}^{\mathrm{e}}=\dot{\boldsymbol{\varepsilon}}^{\mathrm{e}}-\frac{1}{3} \dot{\varepsilon}_{\mathrm{v}}^{\mathrm{e}} \boldsymbol{I}\right) ; \dot{\boldsymbol{\sigma}}_{\mathrm{d}}$ is the rate of the deviatoric effective stress $\left(=\dot{\boldsymbol{\sigma}}^{\prime}-\frac{1}{3} \operatorname{tr}\left(\dot{\boldsymbol{\sigma}}^{\prime}\right) \boldsymbol{I}\right)$, and $\dot{p}^{\prime}$ the rate of the effective mean stress $\left(=\operatorname{tr}\left(\dot{\boldsymbol{\sigma}}^{\prime}\right) / 3\right)$.

Eq. (7) corresponds to the conventional solid mechanics thermo-elasticity formulation and will be adapted to address cohesive soils.

Fig. 1 represents the response to a heating-cooling cycle, at a constant isotropic stress, of saturated drained Kaolin clay in normally consolidated (NC) and overconsolidated $(\mathrm{OCR}=12$; OCR, overconsolidated ratio) states. The NC sample consolidates during heating with non-linear volume variation. On the contrary, during cooling, the behaviour results in a volume increase. The behaviour over the entire cycle indicates strain irreversibility due to thermal loading. For the highly overconsolidated sample $(\mathrm{OCR}=12)$, the thermal strains are dilatant during heating and almost reversible after the cooling phase. They are considered the thermo-elastic strains. 


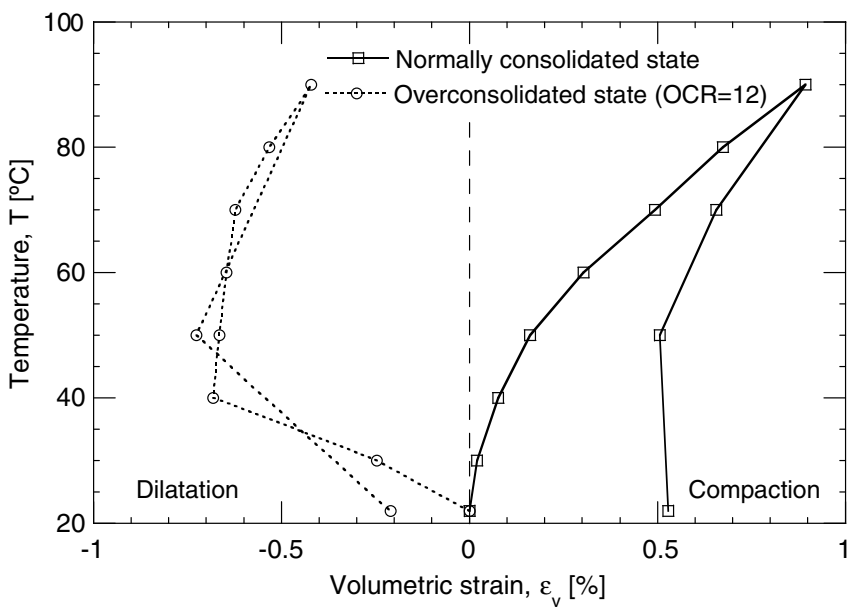

Fig. 1. Volumetric strain of a saturated drained Kaolin clay during thermal cycle $\left(22^{\circ} \mathrm{C} \rightarrow 90^{\circ} \mathrm{C} \rightarrow 22^{\circ} \mathrm{C}\right)$ - confining pressure of $600 \mathrm{kPa}$ [4].

The thermal expansion coefficient of the solid skeleton, $\beta_{\mathrm{s}}^{\prime}$, varies with the overconsolidation ratio, OCR, as well as with temperature, according to Laloui [14]:

$\beta_{\mathrm{s}}^{\prime}=\left(\beta_{\mathrm{s} 0}^{\prime}+\zeta T\right) \cdot \mathrm{OCR}$,

in which $\beta_{\mathrm{s} 0}^{\prime}$ is the isotropic thermal expansion coefficient at reference temperature $T_{0}$, OCR represents the ratio between pre-consolidation stress and the mean effective pressure, $p^{\prime}$, at the reference temperature.

Eq. (8) enables the thermo-elastic strain rate to increase with increasing overconsolidation ratio and temperature as observed in the experimental results. Laloui [15] and Cekerevac and Laloui [5] clearly show that the reversible thermal strains are non-linear.

The mechanical hypo-elastic moduli depend on confining pressure in a non-linear manner [10]:

$K=K_{\text {ref }}\left(\frac{p^{\prime}}{p_{\text {ref }}}\right)^{n}, \quad G=G_{\text {ref }}\left(\frac{p^{\prime}}{p_{\text {ref }}}\right)^{n}$

with $K_{\text {ref }}$ and $G_{\text {ref }}$ being the bulk and shear incremental elastic moduli, respectively, at the reference pressure $p_{\text {ref }}$ (the value of the mean effective stress at which the elastic moduli are measured), and $n$ is a non-linear elasticity exponent. Fig. 2 shows the secant Young's elastic moduli obtained from triaxial shear tests performed at 22 and $90{ }^{\circ} \mathrm{C}$ at both normally consolidated (NC) and overconsolidated (OC) states. The initial elastic moduli increase with increased confining pressure and this effect is more significant than the increase observed as a result of increasing temperature. Hence, the thermal dependence of the elastic moduli is neglected (Eq. (9)).

\subsection{Thermo-plastic component}

As summarised previously, the constitutive model contains four coupled plastic mechanisms: three deviatoric (numbered 1-3) and one isotropic (4).
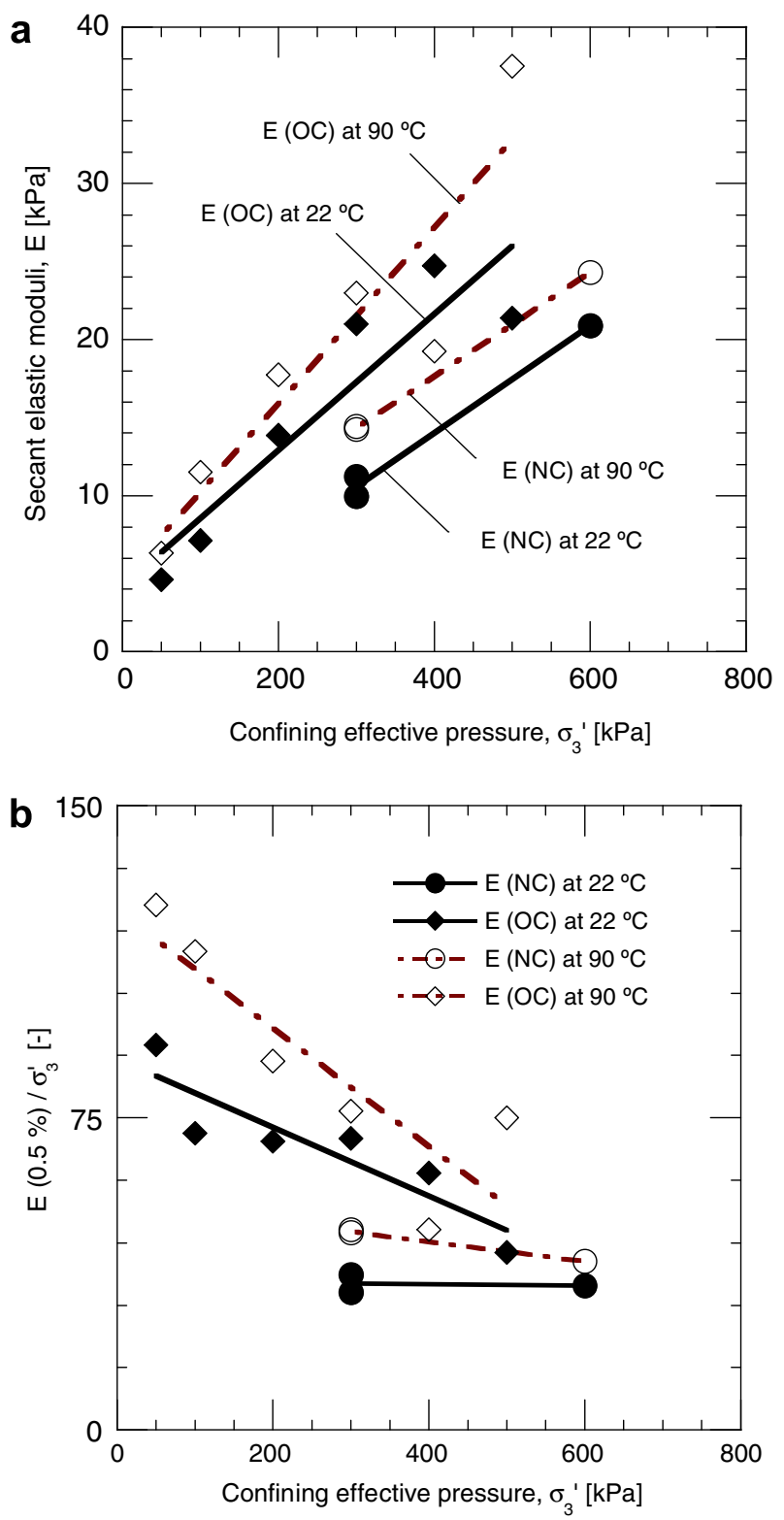

Fig. 2. Secant Young's (elastic) moduli for axial strain of $0.5 \%$ obtained from drained saturated triaxial shear tests at ambient $\left(22^{\circ} \mathrm{C}\right)$ and high $\left(90^{\circ} \mathrm{C}\right)$ temperatures; confining pressure $600 \mathrm{kPa}$. (a) Secant Young moduli and (b) normalised secant Young moduli [5].

\subsubsection{Isotropic mechanism}

Pre-consolidation pressure, $\sigma_{c}^{\prime}$, is considered a pseudoelastic limit that separates "elastic" pre-yield from "plastic" post-yield behaviour under isotropic conditions. The isotropic yield limit is expressed as [16]

$f_{4}=p^{\prime}-\sigma_{\mathrm{c}}^{\prime}$.

As the slope $\beta$ of the normal consolidation line is independent of temperature $[15,5]$, the pre-consolidation pressure can be related to volumetric plastic strain, $\varepsilon_{\mathrm{v}}^{\mathrm{p}}$, by

$\sigma_{\mathrm{c}}^{\prime}=\sigma_{\mathrm{c} T}^{\prime} \exp \left\{\beta \varepsilon_{\mathrm{v}}^{\mathrm{p}}\right\}$,

where $\sigma_{\mathrm{c} T}^{\prime}$ is the value of the pre-consolidation pressure at a given temperature $T$. It is obtained through a dependence 
law with respect to temperature considering a decrease in pre-consolidation pressure with increasing temperature (Fig. 3) [16]

$\sigma_{\mathrm{c} T}^{\prime}=\sigma_{\mathrm{c} T_{0}}^{\prime}\left\{1-\gamma \log \left[T / T_{0}\right]\right\}$.

$\sigma_{\mathrm{c} T_{0}}^{\prime}$ is the reference pre-consolidation stress at the initial temperature $T_{0}$. The complete expression of the isotropic plastic yield limit is thus given by

$f_{4}=p^{\prime}-\sigma_{\mathrm{c} T_{0}}^{\prime} \exp \left\{\beta \varepsilon_{\mathrm{v}}^{\mathrm{p}}\right\}\left\{1-\gamma \log \left[T / T_{0}\right]\right\}$.

The proposed yield function (Eq. (13)) under isothermal conditions $\left(T=T_{0}\right)$ produces elastic deformations for $p^{\prime}<\sigma_{\mathrm{c}}^{\prime}$. In such a case, the yield point that defines pre-consolidaiton pressure corresponds to an abrupt change of the slope in the volumetric strain-ln $p^{\prime}$ plane. To achieve a more realistic, smooth transition from the elastic to the plastic domain, a parameter, $r_{i}$, is introduced [10]

$r_{i}=r^{\mathrm{e}}+\frac{\varepsilon_{\mathrm{vi}}^{\mathrm{p}}}{c+\varepsilon_{\mathrm{vi}}^{\mathrm{p}}}$,

where $c$ is the parameter that regulates the rate of mobilisation of the isotropic mechanism. $r_{i}$ varies from $r^{\mathrm{e}}$, which defines the size of the elastic domain, to 1 at a fully mobilised state. $\varepsilon_{\mathrm{vi}}^{\mathrm{p}}$ is the volumetric plastic strain induced by the isotropic mechanism.

Thus, the final form of the isotropic mechanism becomes

$f_{4}=p^{\prime}-\sigma_{\mathrm{c} T_{0}}^{\prime} \exp \left(\beta \varepsilon_{\mathrm{v}}^{\mathrm{p}}\right) \cdot\left\{1-\gamma \log \left\{\left[T_{0}+\Delta T\right] / T_{0}\right\}\right\} r_{i}$.

\subsubsection{Deviatoric mechanisms}

Three deviatoric yield surfaces are written in the three orthogonal planes (mechanisms $k ; k=\{1,2,3\}$ ) of stress space. In each plane, a plane plastic strain hypothesis is assumed and a limit criterion similar to that of the Mohr-Coulomb model is obtained (Fig. 4) and its yield function is that of Cam-clay. The deviatoric yield surface for a mechanism $k$ is proposed as

$f_{k}=q_{k}-p_{k} F_{k} r_{k} \sin \phi$,

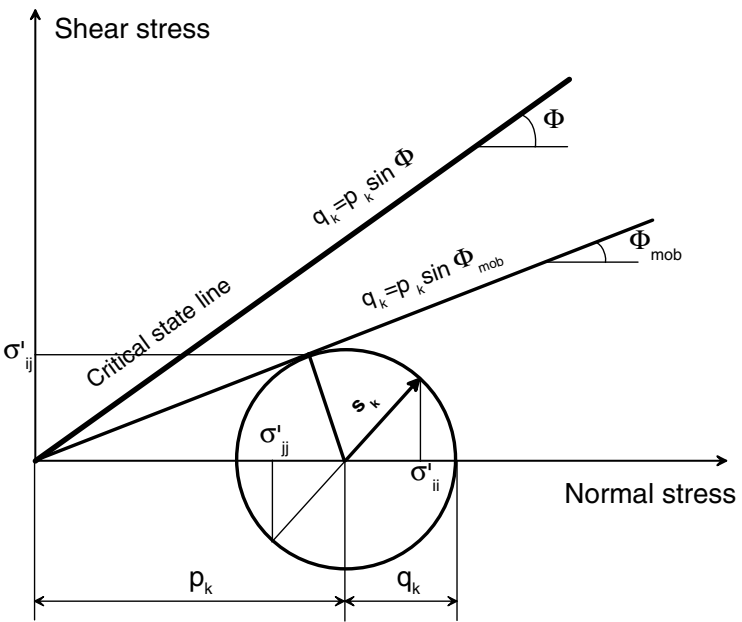

Fig. 4. Stress state in the $(i j)$ plane of the deviatoric mechanism $k-$ Hujeux model [10].

where $p_{k}$ and $q_{k}$ are the reduced mean effective stress and deviatoric stress, respectively, in the plane of the considered mechanism $k$ (Fig. 4), given as

$q_{k}=\left\|\mathbf{s}_{k}\right\|=\frac{1}{2}\left[\left(\sigma_{i i}^{\prime}-\sigma_{j j}^{\prime}\right)^{2}+4 \sigma_{i j}^{\prime 2}\right]^{1 / 2}$,

$p_{k}=\frac{\left(\sigma_{i i}^{\prime}+\sigma_{j j}^{\prime}\right)}{2}$,

with the vector $\mathbf{s}_{k}=\left(\frac{1}{2}\left(\sigma_{i i}^{\prime}-\sigma_{j j}^{\prime}\right), \sigma_{i j}^{\prime}\right)$. We note that $\sigma_{i j}^{\prime}$ is a component of the tensor $\boldsymbol{\sigma}^{\prime}$ (indicial ${ }^{k}$ notation is not used here). The index $k$ is linked to the ordered couples $\{i, j\}$ by $k=\{3,2,1\}, \quad i, j=\{1,2\},\{1,3\},\{2,3\}$.

This means, for example, that when $k=3$ this implies $\{i$, $j\}=\{1,2\}$. The function $F_{k}$ takes into account the volumetric hardening or softening:

$F_{k}=1-b\left(\ln \frac{d p_{k}}{\sigma_{\mathrm{c} T_{0}}^{\prime}}-\beta \varepsilon_{\mathrm{v}}^{\mathrm{Tp}}\right)$

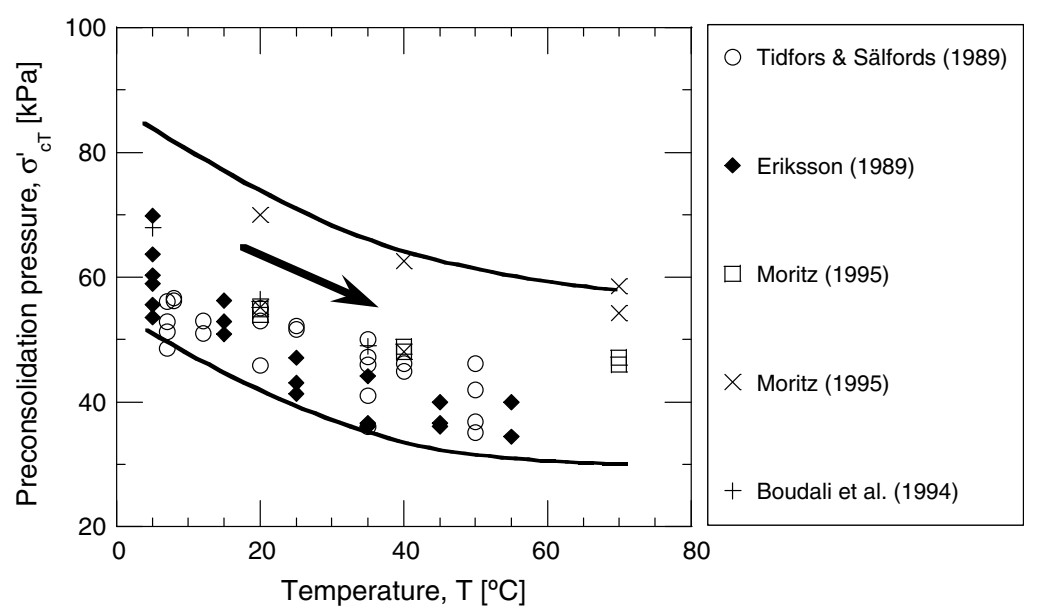

Fig. 3. Influence of temperature on pre-consolidation pressure [16]. (See above mentioned references for further information.) 
with $b$ being representing a parameter that controls the shape of the yield surface $(b=0$ Mohr-Coulomb; $b=1$ Cam-clay). The parameter $d$ represents, by neglecting the elastic part of the strain, the distance in the void ratio In mean effective stress plane, between the critical state line and the parallel isotropic consolidation line $(d=\exp (1)$ in the original Cam-clay).

The internal variable $r_{k}$ represents the ratio of the mobilised friction over the maximum friction that may be mobilised. Its introduction permits the differentiated treatment of the behaviour in elastic, hysteretic and mobilised domains introduced by other model parameters termed $r_{\text {el }}, r_{\text {hys }}$ and $r_{\text {mob }}$ [10]. Variables $F_{k}$ and $r_{k}$ both describe isotropic hardening, but have different origins and different evolution rules. The first introduces the isotropic hardening associated with plastic volumetric strain, similar to the Cam-clay model. The second represents isotropic hardening caused by the deviatoric plastic strain in each mechanism. The deviatoric and isotropic hardening mechanisms are coupled due to the first type of hardening, as the second describes the position of the individual physical plane representing the deviatoric mechanism.

$\phi$ is the friction angle at the critical state, which is only slightly affected by temperature [5]. A linear law is proposed to describe the dependence

$\phi=\phi_{0}+g\left(T-T_{0}\right)$,

where $\phi_{0}$ is the value of the friction angle at the reference temperature $T_{0}$ and $g$ is an average slope of variation of the friction angle with temperature, which can be either positive or negative. The values of $g$ and $\phi$ obtained from the experiments always result in positive values for friction angles in the considered temperature range.

The deviatoric yield limit reduces with increasing temperature. Fig. 5 shows the experimentally observed thermal

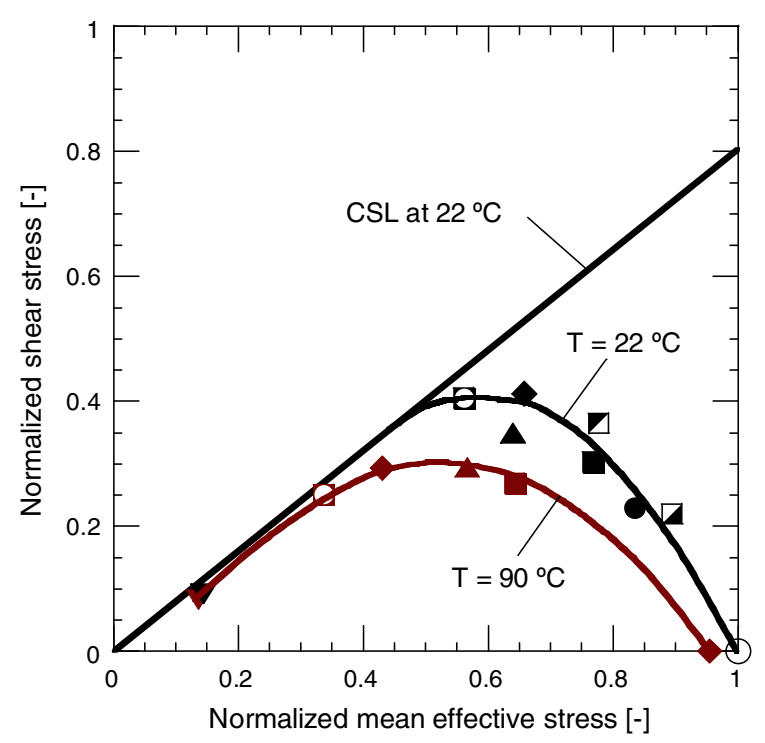

Fig. 5. Normalised yield limits envelope of a saturated Kaolin clay at $T=22$ and $90^{\circ} \mathrm{C}$; CSL is the critical state line [5]. yielding envelope for saturated Kaolin clay at 22 and $90{ }^{\circ} \mathrm{C}$ [5]. To sustain constant effective stress during drained heating, thermal softening must be compensated by strain hardening in normally consolidated or lightly overconsolidated samples [9]. For the results presented in Fig. 5 the samples were first consolidated at a mean pressure of $600 \mathrm{kPa}$. After, each sample was unloaded to a specific pressure, which corresponds to overconsolidation ratios of $1.2-12$. The temperature of the samples was increased to $90{ }^{\circ} \mathrm{C}$ and the samples were sheared in drained conditions. Thus, the initial specific volume (before shearing) is different for the different samples, depending on the values of mean stress and temperature. During drained shearing, the paths moved through an infinite number of constant specific volume, $v$, sections of the Roscoe surface. As a result, the yield points were situated in different $v=$ constant planes. To present the obtained results in the same plane, they were scaled down to the same specific volume. The scaling factor could be defined as the equivalent pressure on the normal consolidation line $(N C L)$ at a given specific volume, $p_{\mathrm{e}}^{\prime}$. The value $p_{\mathrm{e}}^{\prime}$ is obtained from the normal consolidation line by using a specific volume during yielding [5], and the equivalent pressure is obtained by tracing a line $v=$ constant to the NCL and reading the corresponding mean effective stress value. So, the stress quantities plotted in Fig. 5 are the effective mean pressure over $p_{\mathrm{e}}^{\prime}$ ( $x$-axis) and the shear stress over $p_{\mathrm{e}}^{\prime}(y$-axis).

\subsection{Plastic flow rule}

The volumetric thermo-plastic strain rate of the isotropic mechanism, $\dot{\varepsilon}_{\mathrm{vi}}^{\mathrm{Tp}}$, is expressed through the following consistency equation:

$\dot{f}_{4}=\partial_{p^{\prime}} f_{4} \dot{p}^{\prime}+\partial_{T} f_{4} \dot{T}+\partial_{\varepsilon_{\mathrm{vi}}^{\mathrm{Tp}}} f_{4} \dot{\varepsilon}_{\mathrm{vi}}^{\mathrm{Tp}}+\partial_{r_{i}} f_{4} \dot{r}_{i}$.

Thus,

$\dot{\varepsilon}_{\mathrm{vi}}^{\mathrm{Tp}}=-\frac{\partial_{p^{\prime}} f_{4} \dot{p}^{\prime}+\partial_{T} f_{4} \dot{T}+\partial_{r_{i}} f_{4} \dot{r}_{i}}{\partial_{\varepsilon_{\mathrm{vi}}} f_{4}}$.

The plastic flow rule is also derived for each deviatoric mechanism $k$, and the plastic strain rate tensor is represented by its trace (first invariant), $\left(\dot{e}_{\mathrm{v}}^{\mathrm{Tp}}\right)_{k}$ and the vector $\left(\dot{\mathbf{e}}_{\mathrm{d}}^{\mathrm{Tp}}\right)_{k}$, which are both defined by

$$
\begin{aligned}
& \left(\dot{e}_{\mathrm{v}}^{\mathrm{Tp}}\right)_{k}=\left(\dot{\varepsilon}_{i i}^{\mathrm{Tp}}+\dot{\varepsilon}_{j j}^{\mathrm{Tp}}\right)_{k}=\dot{\lambda}_{k} \cdot\left(\Psi_{\mathrm{v}}\right)_{k}, \\
& \left(\dot{\mathbf{e}}_{\mathrm{d}}^{\mathrm{Tp}}\right)_{k}=\left(\left(\dot{\varepsilon}_{i i}^{\mathrm{Tp}}-\dot{\varepsilon}_{j j}^{\mathrm{Tp}}\right), \dot{\varepsilon}_{i j}^{\mathrm{Tp}}\right)_{k}=\dot{\lambda}_{k} \cdot\left(\boldsymbol{\Psi}_{\mathrm{d}}\right)_{k} .
\end{aligned}
$$

For the deviatoric component, $\left(\dot{\mathbf{e}}_{\mathrm{d}}^{\mathrm{Tp}}\right)_{k}$, the direction of plastic flow in each mechanism is obtained by assuming the normality rule in the deviatoric plane. For the volumetric component, a modified Roscoe's dilatancy rule is applied [21]. $\left(\Psi_{\mathrm{v}}\right)_{k}$ and $\left(\Psi_{\mathrm{d}}\right)_{k}$ are plastic potential gradient defined by

$$
\left(\Psi_{\mathrm{v}}\right)_{k}=-\alpha_{k}\left(\sin \psi-\frac{\left[\mathbf{s}_{k} \cdot\left(\boldsymbol{\Psi}_{\mathrm{d}}\right)_{k}\right]}{p_{k}}\right),
$$


where $\psi$ is the dilatancy angle corresponding to the characteristic line. The parameter $\alpha_{k}$ adjusts the dilatancy angle during shearing, which varies with $r_{k}$ depending on the domain (elastic, hysteretic or mobilised) of mechanical behaviour (for soft clays, $\alpha_{k}$ is close to 1 ). When introducing the evolution law for internal variable $r_{k}$ :

$\dot{r}_{k}=\dot{\lambda}_{k} l_{k}$,

where $l$ is a constitutive function expressed by

$l_{k}=\frac{\left(1-r_{k}\right)^{2}}{a}$.

$a\left(r_{k}\right)$ is a parameter defined as

$a=a_{\mathrm{c}}+\left(a_{\mathrm{m}}-a_{\mathrm{c}}\right) \alpha_{k}$

With $a_{\mathrm{c}}$ and $a_{\mathrm{m}}$ being material parameters.

\subsection{Calculation of thermo-plastic strains}

To make the calculations of the thermo-plastic strain rates possible, the plastic multipliers $\dot{\lambda}_{k}(k=1,2,3,4)$ must be determined (Eq. (4)). To present the calculations for the four mechanisms in a coherent manner, the plastic multiplier of the isotropic mechanism will be called $\dot{\lambda}_{4}$. The flow rules may than be formulated as the linear complementary condition

$\dot{\lambda}_{k} \dot{f}_{k}=0, \quad k=\{1,2,3,4\}, \quad \dot{\lambda}_{k} \geqslant 0, \quad \dot{f}_{k} \leqslant 0$,

which gives

$$
\begin{aligned}
& \dot{\lambda}_{k}\left(\partial_{\boldsymbol{\sigma}^{\prime}} f_{k} \cdot \dot{\boldsymbol{\sigma}}^{\prime}+\partial_{r_{k}} f_{k} \cdot \dot{r}_{k}+\partial_{\varepsilon_{\mathrm{v}} \mathrm{T}} f_{k} \cdot \dot{\varepsilon}_{\mathrm{v}}^{\mathrm{Tp}}+\partial_{T} f_{k} \cdot \dot{T}\right)=0, \\
& \quad k=\{1,2,3,4\},
\end{aligned}
$$

which is the condition in which the material is maintained in the yielding stage, i.e. the stress point remains on the yield surface, when

$\dot{\lambda}_{k}>0 \quad$ and $\quad \dot{f}_{k}=0 \quad k=\{1,2,3,4\}$.

Derivations of the yield mechanisms give

$\boldsymbol{\Phi}_{k}=\partial_{\sigma^{\prime}} f_{k}$

$\dot{\boldsymbol{\sigma}}^{\prime}=\mathbf{D} \cdot \partial_{t} \boldsymbol{\varepsilon}^{\mathrm{e}}=\mathbf{D} \cdot\left(\dot{\boldsymbol{\varepsilon}}-\frac{\beta_{\mathrm{s}}^{\prime}}{3} \dot{T} \boldsymbol{I}-\sum_{k=1}^{4} \dot{\lambda}_{k} \cdot(\boldsymbol{\Psi})_{k}\right)$,

where

$\partial_{t} \dot{\varepsilon}_{\mathrm{v}}^{\mathrm{Tp}}=\sum_{k=1}^{4} \dot{\lambda}_{k} \cdot\left(\Psi_{\mathrm{v}}\right)_{k}$.

The other auxiliary functions for the deviatoric yield mechanisms are (with $p_{\mathrm{c}}=\sigma_{\mathrm{c} T_{0}}^{\prime} / d$ )

$\partial_{r_{k}} f_{k}=-p_{k}\left(1-b \ln \frac{p_{k}}{p_{\mathrm{c}}}\right) \sin \phi$

$\partial_{\varepsilon_{\mathrm{v}}} f_{k}=-p_{k} b \beta r_{k} \sin \phi$

$\partial_{\mathrm{T}} f_{k}=-p_{k}\left(1-b \ln \frac{p_{k}}{p_{\mathrm{c}}}\right) r_{k} g \cos \phi, \quad k=\{1,2,3\}$, and for the isotropic mechanism

$$
\begin{aligned}
& \partial_{r_{4}} f_{4}=-\sigma_{\mathrm{c} T_{0}}^{\prime} \exp \left(\beta \varepsilon_{\mathrm{v}}^{\mathrm{Tp}}\right)\left\{1-\gamma \log \left\{\left[T_{0}+\Delta T\right] / T_{0}\right\}\right\}, \\
& \partial_{\varepsilon_{\mathrm{v}}} f_{4}=-\sigma_{\mathrm{c} T_{0}}^{\prime} \exp \left(\beta \varepsilon_{\mathrm{v}}^{\mathrm{Tp}}\right)\left\{1-\gamma \log \left\{\left[T_{0}+\Delta T\right] / T_{0}\right\}\right\} \\
& \left\{\beta r_{4}+c /\left(c+\varepsilon_{\mathrm{v}}^{\mathrm{Tp}}\right)^{2}\right\}, \\
& \partial_{\mathrm{T}} f_{4}=\sigma_{\mathrm{c} T_{0}}^{\prime} \exp \left(\beta \varepsilon_{\mathrm{v}}^{\mathrm{Tp}}\right) r_{4} \frac{\gamma}{\ln 10 T}, \quad k=\{4\} .
\end{aligned}
$$

It can be denoted that

$H_{T k}=\partial_{T} f_{k} \cdot \dot{T}$.

Introducing derivations (Eqs. (31)-(36)) into Eq. (29), the following system of equations is obtained:

$$
\begin{aligned}
\boldsymbol{\Phi}_{k} & \cdot\left[\mathbf{D} \cdot \dot{\boldsymbol{\varepsilon}}-\mathbf{D} \cdot \frac{\beta_{\mathrm{s}}^{\prime}}{3} \dot{T} \boldsymbol{I}-\sum_{k=1}^{4} \dot{\lambda}_{k} \cdot \mathbf{D} \cdot(\boldsymbol{\Psi})_{k}\right]+\partial_{r_{k}} f_{k} \dot{\lambda}_{k} l_{k} \\
& +\partial_{\varepsilon_{\mathrm{v}}} f_{k} \sum_{k=1}^{4} \dot{\lambda}_{k}\left(\Psi_{\mathrm{v}}\right)_{k}+H_{T k} \\
& =0, \quad k=\{1,2,3,4\} .
\end{aligned}
$$

After rearranging this equation for one mechanism $k$, the following is obtained:

$$
\begin{aligned}
\boldsymbol{\Phi}_{k} & \cdot \mathbf{D} \cdot \dot{\boldsymbol{\varepsilon}}-\boldsymbol{\Phi}_{k} \cdot \mathbf{D} \cdot \frac{\beta_{\mathrm{s}}^{\prime}}{3} \dot{T} \boldsymbol{I}+H_{T k} \\
& -\left\{\sum_{i=1}^{4} \dot{\lambda}_{i} \boldsymbol{\Phi}_{k} \cdot \mathbf{D} \cdot(\boldsymbol{\Psi})_{i}-\partial_{r_{k}} f_{k} \dot{\lambda}_{k} l_{k}-\partial_{\varepsilon_{\mathrm{v}}} f_{k} \sum_{i=1}^{4} \dot{\lambda}_{i}\left(\Psi_{\mathrm{v}}\right)_{i}\right\} \\
& =0, \quad k=\{1,2,3,4\} .
\end{aligned}
$$

Note that in Eq. (38), in the case where the index $k$ was used for summation, it has been changed to the index $i$ in order to avoid confusion. Rearranging this equation, the following is obtained:

$$
\begin{aligned}
& \boldsymbol{\Phi}_{k} \cdot \mathbf{D} \cdot \dot{\boldsymbol{\varepsilon}}-\boldsymbol{\Phi}_{k} \cdot \mathbf{D} \cdot \frac{\beta_{s}^{\prime}}{3} \dot{T} \boldsymbol{I}+H_{T k} \\
& -\left\{\sum_{i=1}^{4} \dot{\lambda}_{i}\left[\boldsymbol{\Phi}_{k} \cdot \mathbf{D} \cdot(\boldsymbol{\Psi})_{i}-\left(\partial_{r_{k}} f_{k} l_{k}\right) I_{k i}-\left(\partial_{\varepsilon_{\mathrm{v}}} f_{k}\left(\Psi_{\mathrm{v}}\right)_{i}\right)\right]\right\} \\
& =0, \quad k=\{1,2,3,4\} .
\end{aligned}
$$

If the following is denoted:

$H_{r k}=-\partial_{r_{k}} f_{k} l_{k}$,

$\Pi_{\mathrm{v} k i}=-\partial_{\varepsilon_{\mathrm{v}}} f_{k}\left(\Psi_{\mathrm{v}}\right)_{i}$,

$H_{T}=-\boldsymbol{\Phi}_{k} \cdot \mathbf{D} \cdot \frac{\beta_{\mathrm{s}}^{\prime}}{3} \dot{T} \boldsymbol{I}$.

The following may be obtained, finally

$$
\begin{aligned}
& \left\{\sum_{i=1}^{4} \dot{\lambda}_{i}\left[\boldsymbol{\Phi}_{k} \cdot \mathbf{D} \cdot(\boldsymbol{\Psi})_{i}+H_{r k}+\Pi_{\mathrm{v} k i}\right]\right\} \\
& =\boldsymbol{\Phi}_{k} \cdot \mathbf{D} \cdot \dot{\boldsymbol{\varepsilon}}+H_{T k}+H_{T}, \quad k=\{1,2,3,4\} .
\end{aligned}
$$


By solving Eq. (43), plastic multipliers whose number is equal to the number of activated mechanisms are obtained; the maximum is 4 .

\subsection{Undrained paths}

The non-isothermal model is expressed using effective stresses so that undrained tests can be considered isochoric strain paths (constant volume). Based on a continuum approach of mass conservation for a saturated two phase mixture, it is possible to derive the Biot's equation [2], which expresses pore water pressure during mechanical loading (by neglecting the convective terms):

$\vartheta \beta_{\mathrm{f}} \partial_{t} u=-\dot{\varepsilon}_{\mathrm{v}}$

$\vartheta$ is the porosity; $u$ the pore water pressure, $\beta_{\mathrm{f}}$ the water compressibility coefficient at constant temperature and $\varepsilon_{\mathrm{V}}$ the total volumetric strain, respectively. Therefore, water pore pressure (LHS of Eq. (44)) variations are only attributed to variations of skeletal volume (compaction or dilation - RHS of Eq. (44)).

\section{Evaluation of the constitutive model}

Performances of the presented non-isothermal elastoplastic model are shown in this section. Four materials (one natural and three remoulded, cohesive) are simulated and the predicted results are compared to the experimental results. For each case, numerical simulations of the experimental paths used for the determination of the model parameters are called back-predictions. The model predictions correspond to the numerical simulations of experimental results that were not used for parameter calibrations.

\subsection{Numerical simulation of the behaviour of natural Boom clay}

Baldi et al. [1] reported a study on the thermo-mechanical behaviour of Boom clay. The experimental program consisted of several coupled thermo-mechanical loading tests and the following are considered:

\section{- Case 1: Heating-cooling cycles at different OCR values}

Specimens were heated to $95^{\circ} \mathrm{C}$ and then cooled to $21.5^{\circ} \mathrm{C}$ at three initial confining stresses $(6,3$ and $1 \mathrm{MPa})$, which correspond to overconsolidation ratios of 1, 2 and 6, respectively (Test TBoom9).

\section{- Case 2: Coupled thermo-mechanical paths}

The second considered case is summarised in Fig. 6 where coupled mean effective stress-temperature loading paths are applied (TBoom10 and TBoom 11 tests). The experimental program included unloading from the initial confining stress of 2 to $1 \mathrm{MPa}(\mathrm{A} \rightarrow \mathrm{B})$, heating from 21.5 to $65^{\circ} \mathrm{C}(\mathrm{B} \rightarrow \mathrm{C})$ and to $95^{\circ} \mathrm{C}(\mathrm{B} \rightarrow \mathrm{E})$, respectively. Then, loading to $8 \mathrm{MPa}(\mathrm{C}$ or $\mathrm{E} \rightarrow \mathrm{D}$ or $\mathrm{F}$ ) was followed by unloading to $1 \mathrm{MPa}\left(\mathrm{D}\right.$ or $\mathrm{F} \rightarrow \mathrm{C}^{\prime}$ or $\mathrm{E}^{\prime}$ ) and finally cooling the initial temperature of $21.5^{\circ} \mathrm{C}\left(\mathrm{E}^{\prime}\right.$ or $\left.\mathrm{C}^{\prime} \rightarrow \mathrm{B}^{\prime}\right)$ was performed.

\subsubsection{Calibration of model parameters}

The model parameters of the Boom clay (Table 1) were obtained using: (i) an isotropic consolidation test from 2 to $8 \mathrm{MPa}$ at room temperature and (ii) the heating path of the Test TBoom9 in a normally consolidated state $\left(p^{\prime}=6 \mathrm{MPa}\right)$.

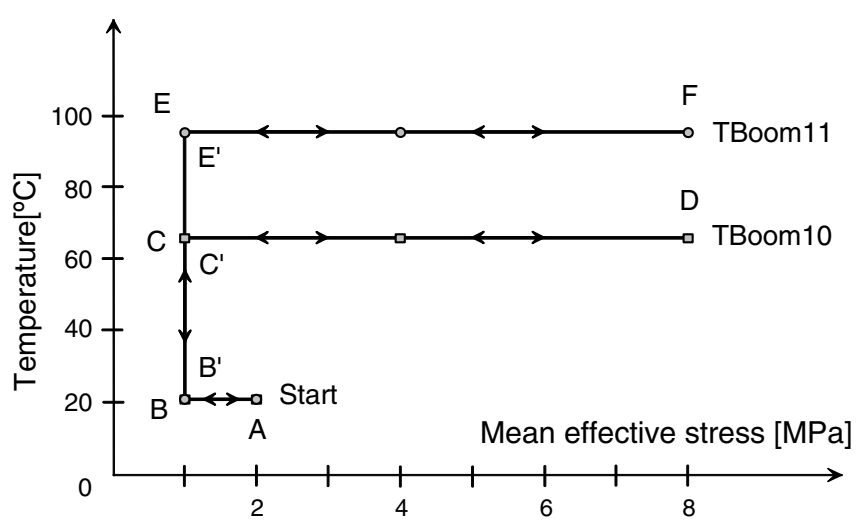

Fig. 6. Test program for TBoom 10 and TBoom11 tests.

Table 1

The model parameters for Boom clay, MC clay, Illite and Kaolin clay

\begin{tabular}{|c|c|c|c|c|}
\hline & Boom clay & MC clay & Illite & Kaolin clay \\
\hline Elastic: $K_{\text {ref }}(\mathrm{MPa}), G_{\text {ref }}(\mathrm{MPa}), n$ (dimensionless) & $150,130,0.4$ & $80,37,0.5$ & $65,30,0.85$ & $70,30,0.68$ \\
\hline $\begin{array}{l}\text { Plastic: } \phi_{0}\left({ }^{\circ}\right), \beta \text { (dimensionless), } p_{\mathrm{c} 0}(\mathrm{MPa}), b \\
\quad(\text { dimensionless) }\end{array}$ & $19.5,14.0,6.0,0.6$ & $18.0,11.0,0.1,0.9$ & $27,18.5,0.775,1.0$ & $\begin{array}{l}20.9 / 23.4,21.0 \\
0.22,0.5\end{array}$ \\
\hline Dilatancy: $\psi\left({ }^{\circ}\right)$ & 23.0 & 18.0 & 27.0 & 22.5 \\
\hline $\begin{array}{l}\text { Hardening: } a_{\mathrm{m}} \text { (dimensionless), } a_{\mathrm{c}} \text { (dimensionless), } c_{\mathrm{m}} \\
\quad \text { (dimensionless), } c_{\mathrm{c}} \text { (dimensionless) }\end{array}$ & $\begin{array}{l}2 \mathrm{E}-3,2 \mathrm{E}-3,4 \mathrm{E}-4 \\
3.7 \mathrm{E}-4\end{array}$ & $\begin{array}{l}0.006,0.005,0.06 \\
0.1\end{array}$ & $\begin{array}{l}0.95,4.5 \mathrm{E}-3 \\
6 \mathrm{E}-3,0.75\end{array}$ & $\begin{array}{l}3.5 \mathrm{E}-3,4 \mathrm{E}-4 \\
0.055,0.09\end{array}$ \\
\hline $\begin{array}{l}\text { Domains: } r^{\mathrm{e}} \text { (dimensionless), } r_{\mathrm{el}} \text { (dimensionless), } r_{\mathrm{hys}} \\
\quad \text { (dimensionless), } r_{\mathrm{mob}}(\text { dimensionless) }\end{array}$ & $0.2,1 \mathrm{E}-3,0.01,0.1$ & $0.08,1 \mathrm{E}-4,0.2,0.9$ & $\begin{array}{l}0.15,1 \mathrm{E}-3,0.01 \\
0.5\end{array}$ & $0.1,1 \mathrm{E}-3,0.01,0.4$ \\
\hline $\begin{array}{l}\text { Thermal: } \beta_{\mathrm{s} 0}^{\prime}\left(\mathrm{C}^{-1}\right), \beta_{\mathrm{f}}^{\prime}\left(\mathrm{C}^{-1}\right), g \text { (dimensionless), } \gamma \\
\quad \text { (dimensionless) }\end{array}$ & $\begin{array}{l}1.3 \mathrm{E}-5,6.3 \mathrm{E}-6 \\
8.5 \mathrm{E}-3,0.18\end{array}$ & $\begin{array}{l}3 \mathrm{E}-5,4 \mathrm{E}-4 \\
35 \mathrm{E}-5,0.10\end{array}$ & $\begin{array}{l}3 \mathrm{E}-5,2 \mathrm{E}-4,0.0 \\
0.246\end{array}$ & $\begin{array}{l}3 \mathrm{E}-5,4 \mathrm{E}-4,0.0 \\
0.075\end{array}$ \\
\hline
\end{tabular}




\subsubsection{Numerical predictions}

\section{- Case 1: Heating-cooling cycle at different OCR values}

The thermal loading path for the NC state $\left(p^{\prime}=6 \mathrm{MPa}\right)$ was used for calibration of the parameter $\gamma$. Therefore, only overconsolidated cases $(\mathrm{OCR}=2$ and 6 ) correspond to the numerical predictions. The comparison between numerical and experimental results is presented in Fig. 7. It is a good prediction of the soil behaviour, both during heating and cooling, for the different values of overconsolidation.

\section{- Case 2: Coupled thermo-mechanical paths}

The numerical predictions of the TBoom 10 test are shown in Fig. 8. In the axial displacement-temperature plane (Fig. 8b), the predictions are quite satisfactory. In the axial displacement-mean effective pressure plane (Fig. 8a), a small difference appears between the predicted and the observed values of axial displacement. This difference occurs during the mechanical consolidation at a temperature of $65^{\circ} \mathrm{C}$ (path CD). However, the final values of axial displacement are similar. When the same path is applied at a higher temperature $\left(T=95^{\circ} \mathrm{C}\right.$; TBoom 11 test $)$, the mechanical unloading produces a different numerical result than that observed (path $\mathrm{FE}^{\prime}$, Fig. 9). The difference remains almost constant until the final stage because the cooling slopes (numerical and experimental) are close (Fig. 9b).

In conclusion, it may be considered that the model is able to reproduce coupled thermo-mechanical paths at initially different stress states.

\subsection{Numerical simulation of reconstituted MC clay}

Experimental results performed on MC clay (Kaolin) have been reported by Kuntiwattanakul [12], Kuntiwattanakul et al. [13] and Towhata et al. [24]. The study detailed the effect of stress history on the volume change caused by heating, as well as on the effect of high temperature (up to

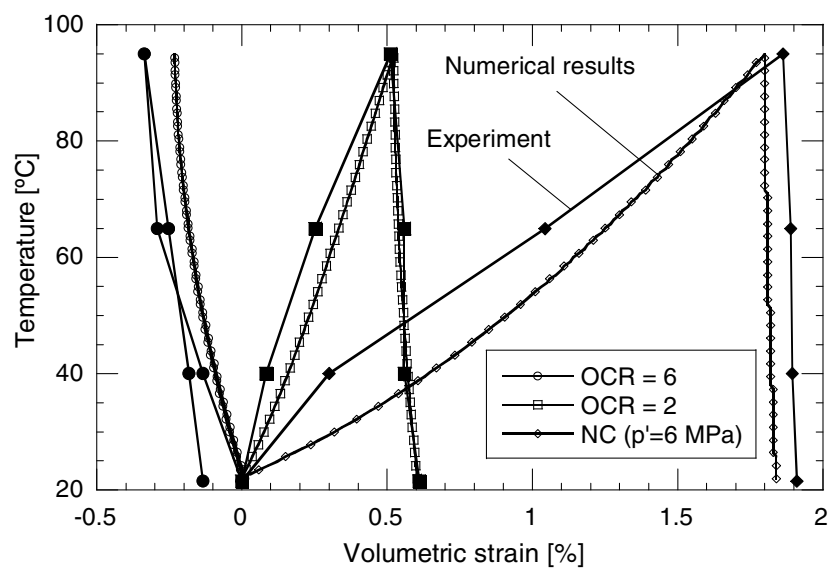

Fig. 7. Comparison of experimental results [1] and numerical predictions (TBoom9).
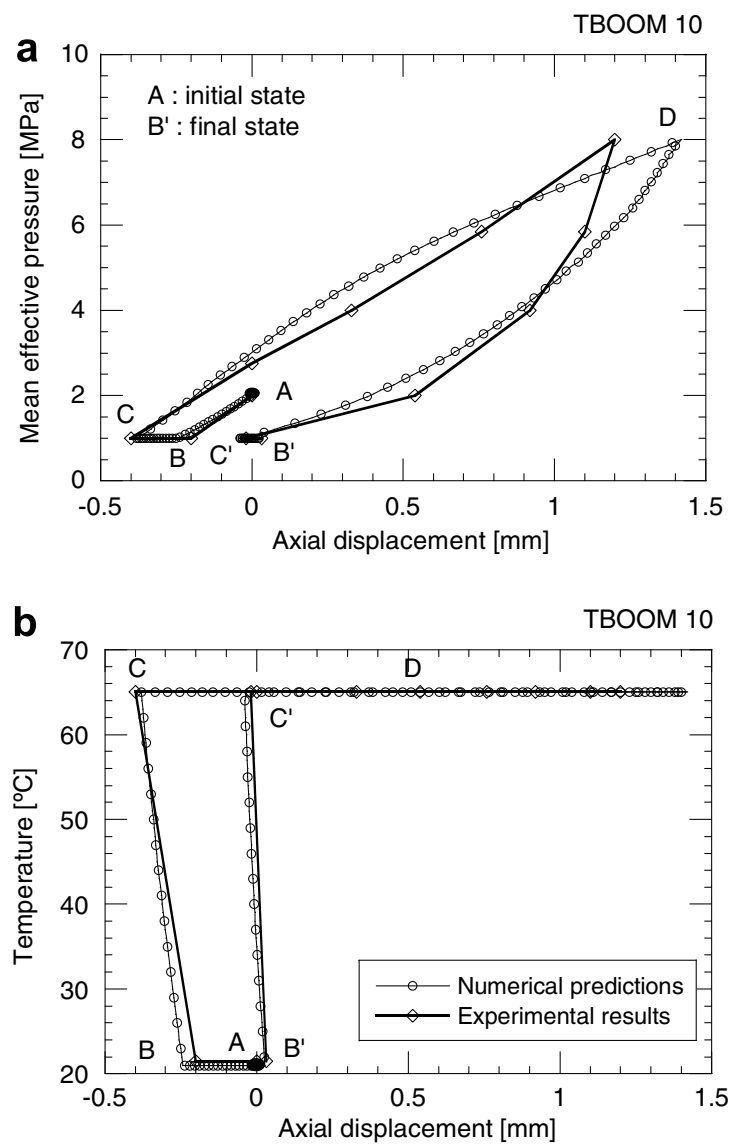

Fig. 8. Numerical simulation of the coupled thermo-mechanical path TBoom 10 (experimental results [1]): (a) axial displacement versus isotropic stress and (b) axial displacement versus temperature.

$90{ }^{\circ} \mathrm{C}$ ) on the undrained shear characteristics of clay in normal and overconsolidated states. The tests were performed on reconstituted samples from clay slurry made by mixing MC (Kaolin) clay and water. The properties of the MC clay are given in Table 2.

\section{- Case 1 : Drained heating test}

In the first case, the specimens were initially consolidated at a pressure of $2230 \mathrm{kPa}$ at ambient temperature. Then, each specimen was unloaded to a specified pressure ranging from 40 to $1280 \mathrm{kPa}$, which corresponds to an overconsolidation ratio between 1.75 and 56 . After, the specimen temperatures were increased stepwise to $90{ }^{\circ} \mathrm{C}$. This path will be referred to as Path 9.

\section{- Case 2 : Undrained triaxial shear tests}

The experimental paths are presented in Fig. 10.

\section{- For normally consolidated samples}

Path $1(0 \rightarrow 1)$ : This is the conventional undrained triaxial test at room temperature: consolidation from 20 to $196 \mathrm{kPa}$ at $20{ }^{\circ} \mathrm{C}$ followed by shearing in undrained conditions. 

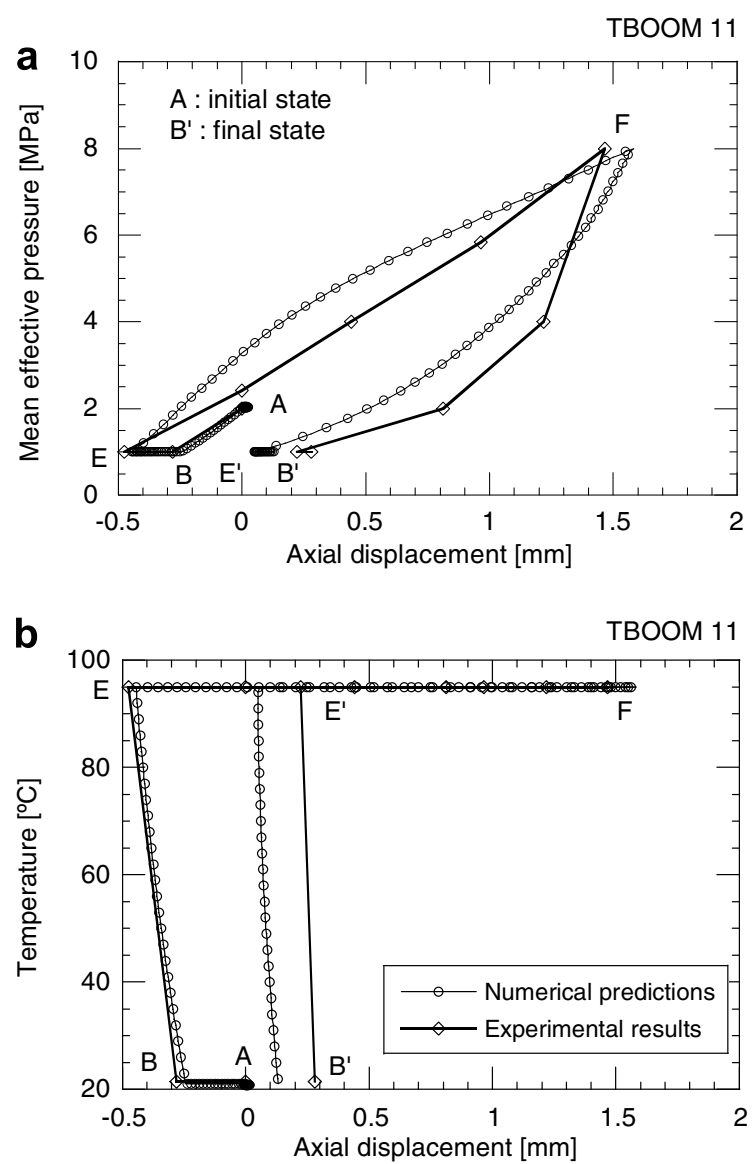

Fig. 9. Numerical simulation of the coupled thermo-mechanical path TBoom11 (experimental results [1]): (a) axial displacement versus isotropic stress and (b) axial displacement versus temperature.

Table 2

Properties of simulated clays

\begin{tabular}{llll}
\hline & $\begin{array}{l}\text { MC clay } \\
{[12]}\end{array}$ & $\begin{array}{l}\text { Kaolin clay } \\
{[5]}\end{array}$ & $\begin{array}{l}\text { Illite } \\
{[8]}\end{array}$ \\
\hline Liquid limit, $w_{\mathrm{L}}(\%)$ & 70 & 45 & 30 \\
Plasticity index, $I_{\mathrm{p}}(\%)$ & 29 & 24 & 9 \\
$\begin{array}{l}\text { Specific gravity, } G_{\mathrm{s}} \\
\quad(\text { dimensionless })\end{array}$ & 2.75 & 2.58 & - \\
$\%<0.002 \mathrm{~mm}(\%)$ & 49 & 45 & - \\
\hline
\end{tabular}

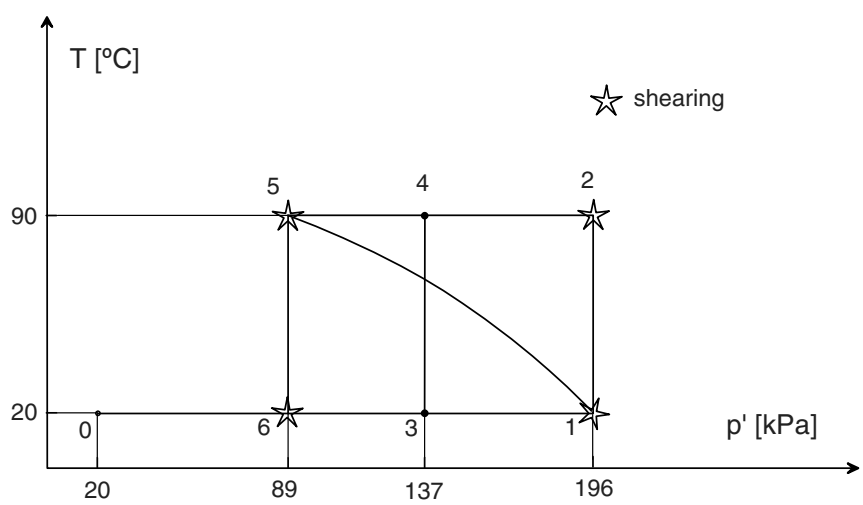

Fig. 10. Experimental paths; stars mark points at which samples are sheared.
Path $2(0 \rightarrow 1 \rightarrow 2)$ : Identical consolidation as Path 1 , followed by a temperature increase to $90{ }^{\circ} \mathrm{C}$ under drained conditions before shearing.

Path $3(0 \rightarrow 3 \rightarrow 4 \rightarrow 2)$ : Consolidation from 20 to $137 \mathrm{kPa}$; temperature increases to $90^{\circ} \mathrm{C}$ under drained conditions; consolidation pressure increases to $196 \mathrm{kPa}$; shearing.

Path $4(0 \rightarrow 1 \rightarrow 2 \rightarrow 1)$ : Consolidation up to $196 \mathrm{kPa}$; heating to $90{ }^{\circ} \mathrm{C}$; cooling under drained conditions; shearing under undrained conditions.

\section{- For overconsolidated samples}

Path $5(0 \rightarrow 1 \rightarrow 6 \rightarrow 5)$ : Consolidation up to $196 \mathrm{kPa}$; unloading (by increase of back pressure) to produce $\mathrm{OCR}=2.2$; temperature increase to $90{ }^{\circ} \mathrm{C}$ under drained conditions; shearing.

Path $6(0 \rightarrow 1 \rightarrow 2 \rightarrow 5)$ : Consolidation up to $196 \mathrm{kPa}$; temperature increase to $90{ }^{\circ} \mathrm{C}$ under drained conditions; unloading to $89 \mathrm{kPa}$; shearing at this OCR of 2.2 .

Path $7(0 \rightarrow 1 \rightarrow 5)$ : Consolidation up to $196 \mathrm{kPa}$; temperature increase to $90{ }^{\circ} \mathrm{C}$ under undrained conditions, which brings about an increase in pore pressure and yields an OCR of about 2.2; shearing.

Path $8(0 \rightarrow 1 \rightarrow 6)$ : Same as Path 5 but without heating.

Experimental data for Paths 1 to 4 and Path 8 are provided twice.

\subsubsection{Calibration of model parameters and back-predictions}

The material parameters for the MC clay were determined using four tests: two triaxial shear tests in $\mathrm{NC}$ and OC states at ambient temperature (Paths 1 and 8), one triaxial test at high temperature $\left(90^{\circ} \mathrm{C}\right.$, Path 2$)$ and one thermal loading (Path 9). The numerical back-prediction of Path 9 is shown in Fig. 11 and has been used to calibrate the parameter $\gamma$. The value of the volumetric thermal expansion coefficient, $\beta_{\mathrm{s} 0}^{\prime}$ is given by Kuntiwattanakul

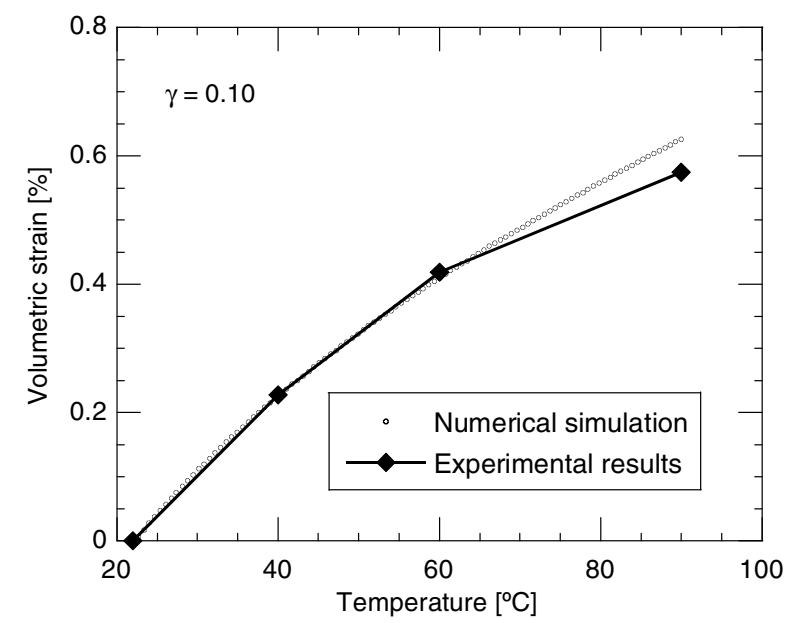

Fig. 11. Numerical back-prediction of the volumetric strain induced by temperature change of normally consolidated specimen; experimental results [12]. 
[12]. The model parameters are provided in Table 1. Backpredictions of the experimental results (made twice for each path) are shown in Fig. 12 (triaxial shear tests in NC and OC states at ambient temperature, Paths 1 and 8) and Fig. 13 (triaxial shear tests in NC state at ambient and high temperatures, Paths 1 and 2). The back-predictions were relatively accurate, except for the pore water generation at small strains.

\subsubsection{Numerical predictions}

\section{- Case 1: Drained heating tests}

The comparison between experimentally observed and numerically predicted void ratio changes caused by temperature in overconsolidated states is given in Fig. 14. The material mainly exhibits thermal dilation for the various OCR values. Compaction is only obtained for $\mathrm{OCR}=1.75$ at temperatures above $70^{\circ} \mathrm{C}$.

The model predicts the experimentally observed behaviour. Particularly, thermo-elastic dilation depends on the value of OCR (higher OCR corresponds to higher dilation). The model can also reproduce the tendency for com- paction obtained with $\mathrm{OCR}=3.5\left(p^{\prime}=640 \mathrm{kPa}\right)$ at about $90{ }^{\circ} \mathrm{C}$ and for $\mathrm{OCR}=1.75\left(p^{\prime}=1280 \mathrm{kPa}\right)$ at about $65^{\circ} \mathrm{C}$. The predicted void ratio values are close to the measured values.

\section{- Case 2: Undrained shearing at different temperatures}

Numerical predictions and experimental results on Paths 3-7 are given in Figs. 15-17. Results are given in the "deviatoric stress $q$-axial strain $\varepsilon_{1}$ " and "part of excess pore pressure $\Delta u_{q}$-axial strain $\varepsilon_{1}$ " planes.

Pore pressure under triaxial conditions is generated either by mean pressure, $\Delta u_{\mathrm{p}}$, or by deviatoric stress $\Delta u_{q}[11]$ :

$\Delta u=\Delta u_{p}+\Delta u_{q}$.

Then,

$\Delta u_{p}=\frac{\left(\Delta \sigma_{1}+2 \Delta \sigma_{3}\right)}{3}$

where $\Delta \sigma_{1}$ and $\Delta \sigma_{3}$ are increments of the principal stress components under triaxial conditions. After, rearranging this equation and considering that $\Delta \sigma_{3}=0$, yields
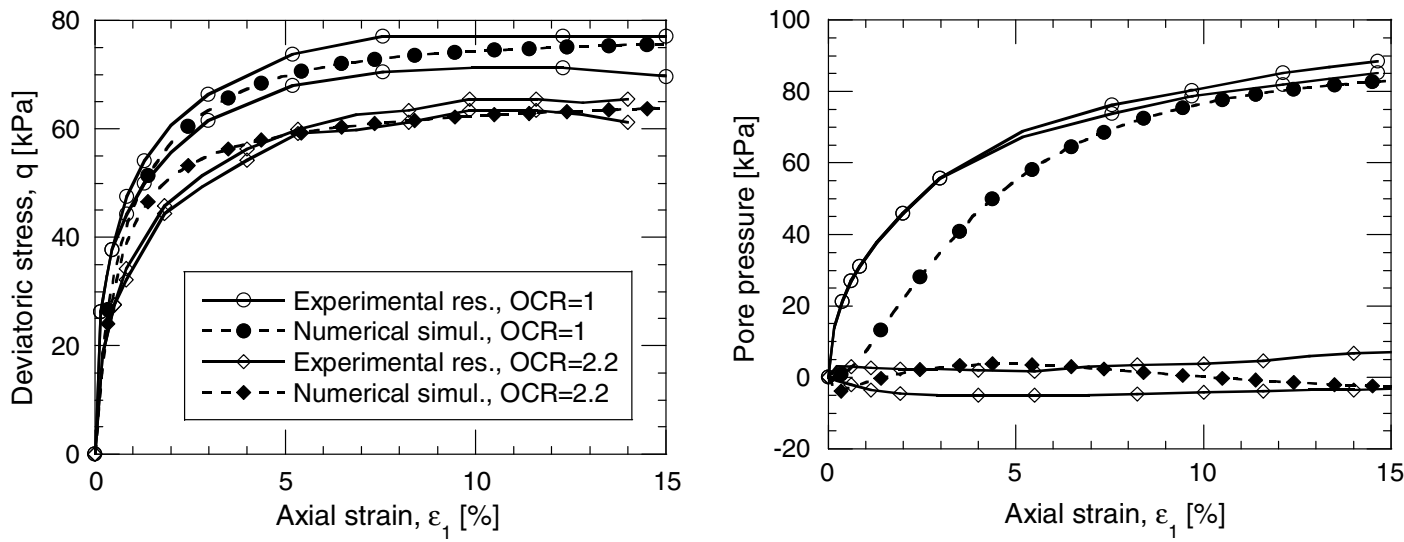

Fig. 12. Undrained shear tests at room temperature in NC and OC states (Paths 1 and 8): comparison between experimental results [12] and numerical back-predictions.
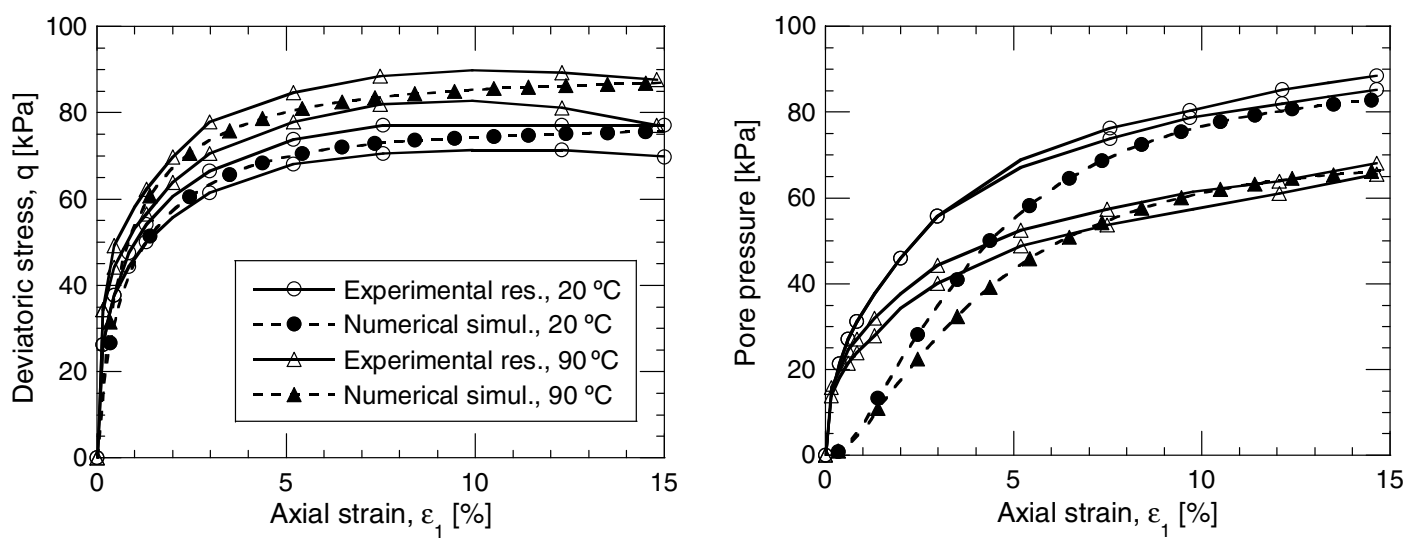

Fig. 13. Undrained shear tests at different temperatures (Paths 1 and 2): comparison between experimental results [12] and numerical back-predictions. 


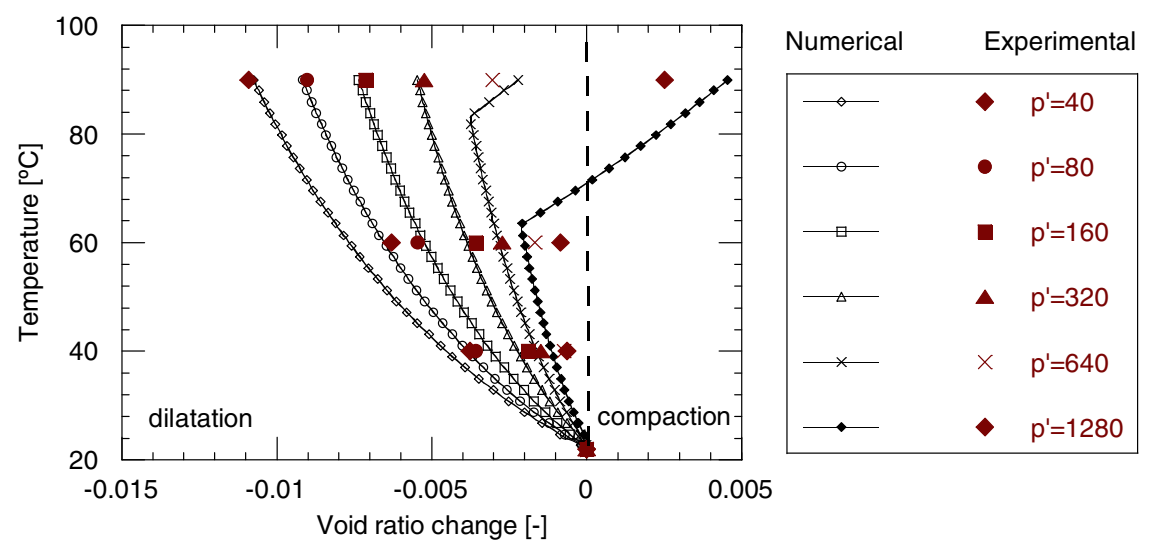

Fig. 14. Comparison of experimental results [12] and numerical predictions.
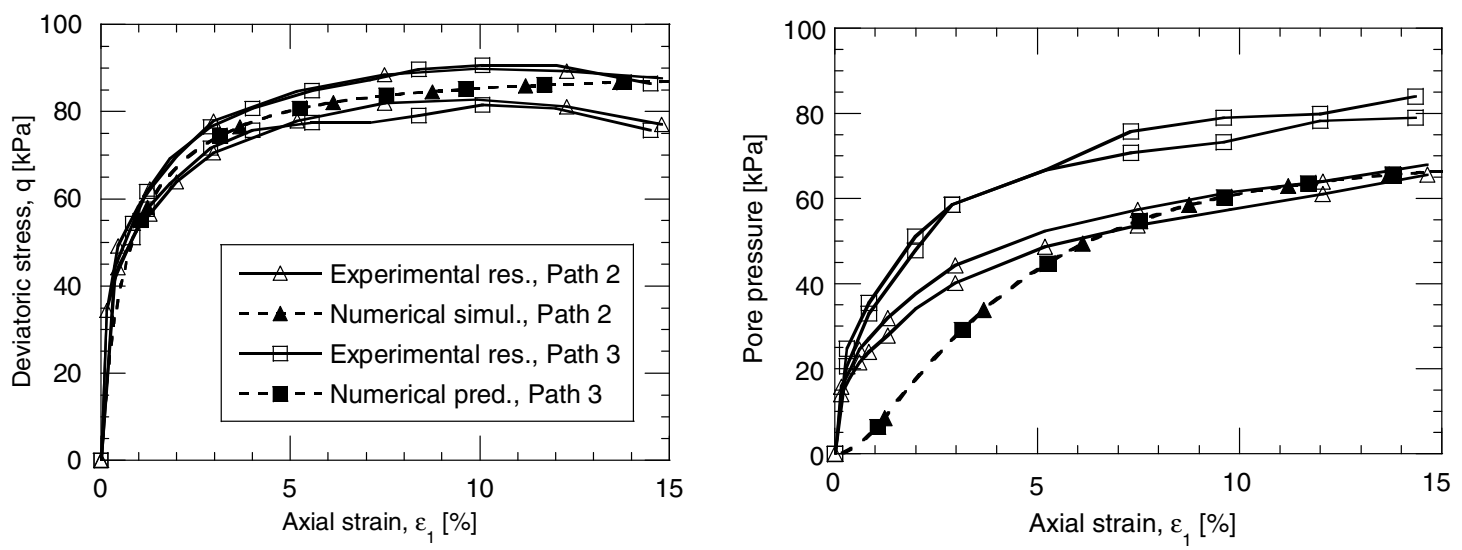

Fig. 15. Undrained shear tests (Paths 2 and 3): comparison between experimental results [12] and numerical predictions.
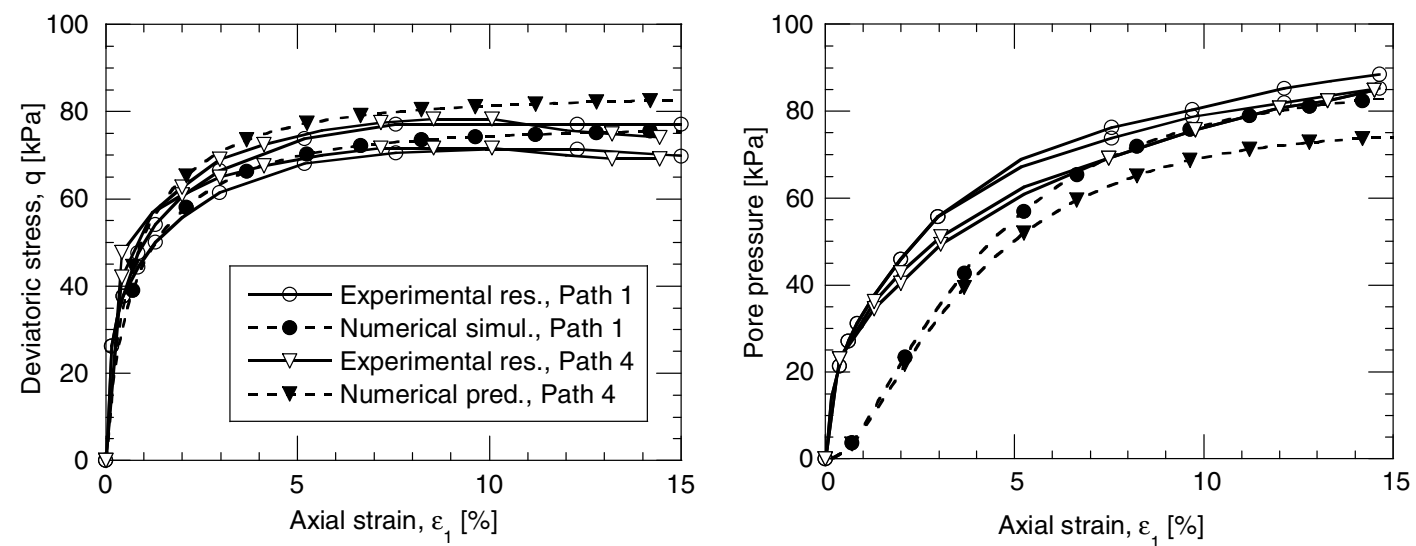

Fig. 16. Undrained shear tests at room temperature without prior heating (Path 1) and after heating/cooling cycle (Path 4): comparison between experimental results [12] and numerical predictions.

$\Delta u_{q}=\Delta u-\frac{\Delta \sigma_{1}}{3}$.

Kuntiwattanakul and co-workers [13] presented their results in terms of pore pressure changes induced by deviatoric stress, $\Delta u_{q}$. To respect this representation, the numerical results are provided in the same manner. Three cases are described in the performance analysis of this model:

Case 2.1 (Paths 2 and 3, Fig. 15): The goal was to identify the influence of the path followed on the undrained mechanical behaviour of clay at high temperature $\left(90^{\circ} \mathrm{C}\right)$. 

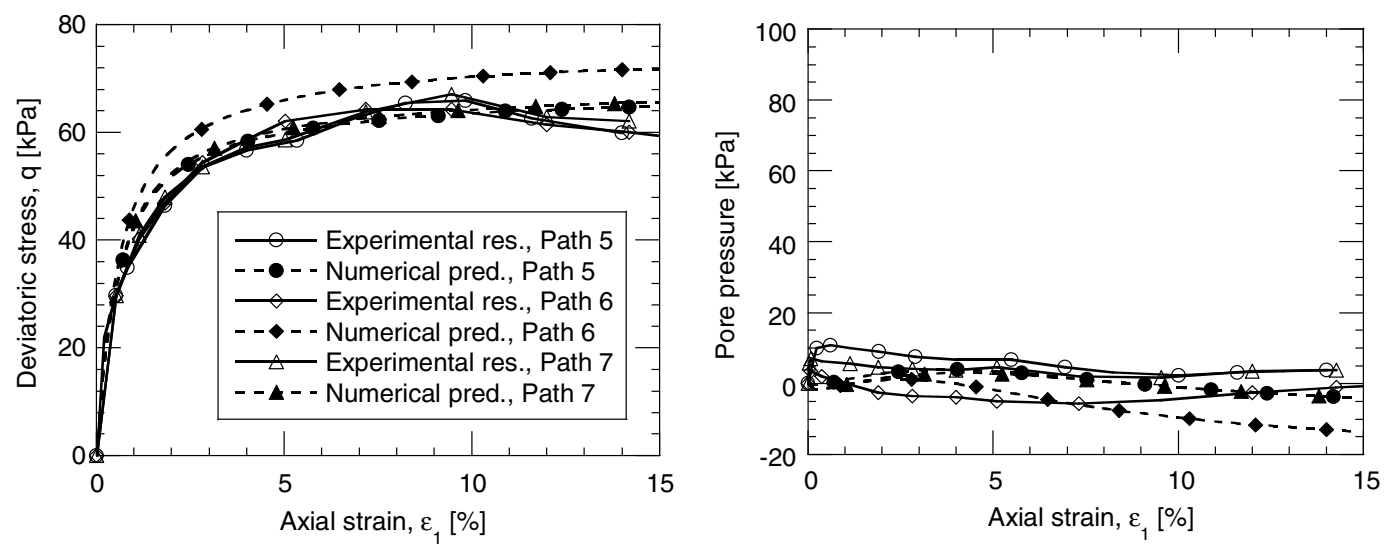

Fig. 17. Undrained shear tests at an OC state (Paths 5,6 and 7): comparison between experimental results [12] and numerical predictions.

On Path 2, consolidation induces mechanical hardening and the increase in temperature produces thermal hardening. On Path 3, mechanical hardening is induced until $137 \mathrm{kPa}$ at ambient temperature and thermal hardening occurs by heating until $90^{\circ} \mathrm{C}$ followed by mechanical hardening until $196 \mathrm{kPa}$. No differences were observed in shear strength for both cases, indicating the negligible influence of the thermal state on mechanical hardening. In terms of the plane $\Delta u_{q}$ versus axial strain, the two paths produce appreciably different results, while the model predictions look identical.

Case 2.2 (Paths 1 and 4, Fig. 16): The aim was to demonstrate the influence of the heating/cooling cycle on undrained shear behaviour. The experimental results indicate a slight thermal effect on the mechanical behaviour in this case. The model shows that thermal loading generates a small amount of hardening. This produces densification, resulting in higher shear strength (Path 4, Fig. 16).

Case 2.3 (Paths 5-7, Fig. 17): This case treats three thermo-mechanical loading paths under an OC condition
$(\mathrm{OCR}=2.2)$. The three paths show similar experimental results for both shear strength and pore pressure generation. The numerical predictions are in accordance with experimental results.

\subsection{Numerical simulation of the behaviour of Kaolin clay}

An extensive experimental study of thermal effects on mechanical behaviour of remoulded Kaolin (CM) clay was outperformed by Cekerevac and Laloui [5]. The samples were tested under several thermo-mechanical paths that can be summarised as follows:

(i) Mechanical isotropic consolidation with loading to a mean effective pressure of $600 \mathrm{kPa}$, followed by mechanical unloading resulting in various overconsolidation ratios $(\mathrm{OCR}=1.0,1.2,1.5,2.0,3.0,6.0$, and 12.0). To ensure saturation of the sample, a constant back-pressure of $100 \mathrm{kPa}$ was applied during isotropic consolidation and was kept constant during
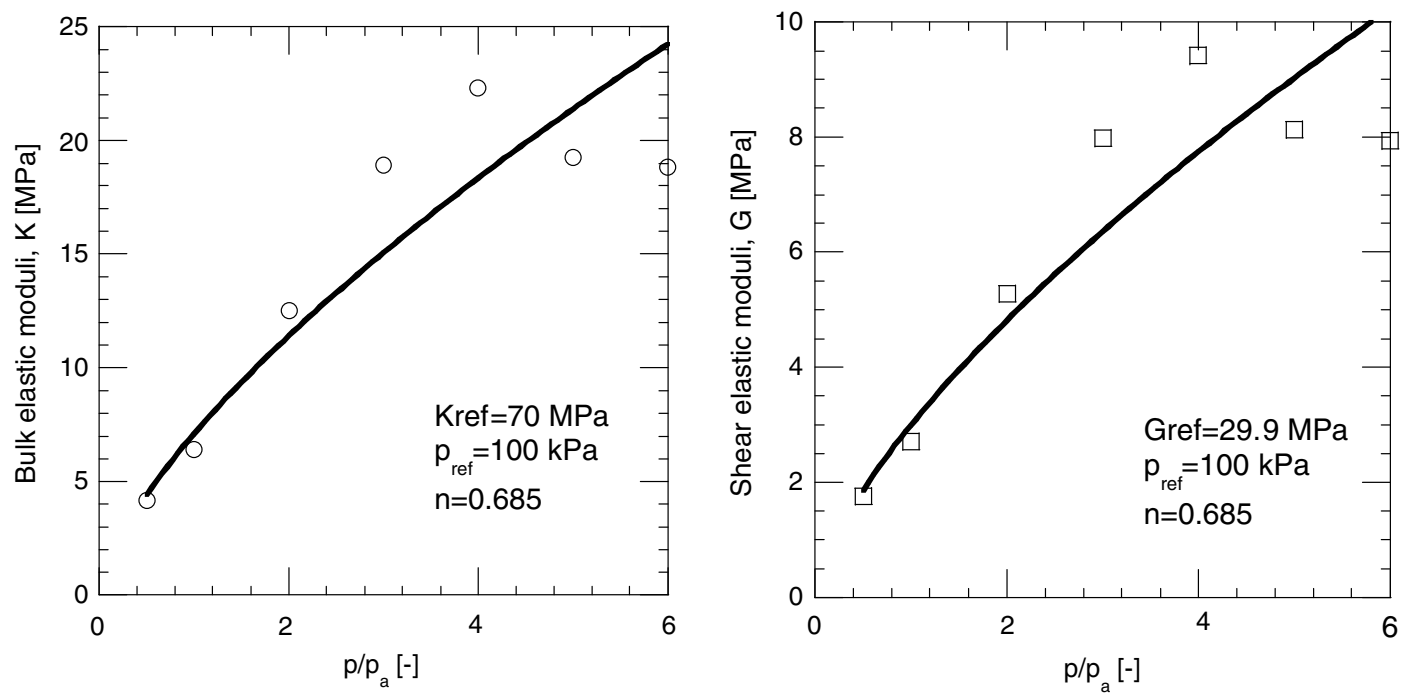

Fig. 18. Evolution of the bulk and shear elastic moduli with cell pressure; experimental results [5] and numerical back-prediction. 
subsequent mechanical and/or thermal loadings. Back-pressure also reduces the evaporation of water in the drainage system.

(ii) Drained heating by stepwise increases of $10^{\circ} \mathrm{C}$ for a $3 \mathrm{~h}$ period.

(iii) Drained shearing, by applying a standard triaxial shearing path, $\delta q / \delta p^{\prime}=3$, with a strain rate of $0.3 \% / \mathrm{h}$.

To quantify the influence of temperature on the stressstrain behaviour of Kaolin, a second set of tests was performed under isothermal conditions. Specimens were first isotropically consolidated to a mean effective pressure of $600 \mathrm{kPa}$, followed by isotropic unloading to different values of OCR $(1.0,1.2,1.5,2.0,3.0,6.0$ and 12.0), both at ambi- ent temperature. Then, specimens were sheared under drained conditions using a strain rate of $0.3 \% / \mathrm{h}$ at this ambient temperature. The properties of the Kaolin clay are provided in Table 2.

\subsubsection{Calibration of model parameters and back-predictions}

The model parameters were obtained using the following test paths: isotropic consolidation test at ambient temperature, two isotropic consolidation tests at high temperature $\left(60\right.$ and $90^{\circ} \mathrm{C}$ ) and two drained shear tests at ambient temperature in $\mathrm{NC}$ and $\mathrm{OC}(\mathrm{OCR}=12)$ states.

Experimental results of the evolution of the bulk and shear moduli are compared with numerical results in Fig. 18. To determine elastic model parameters, the results
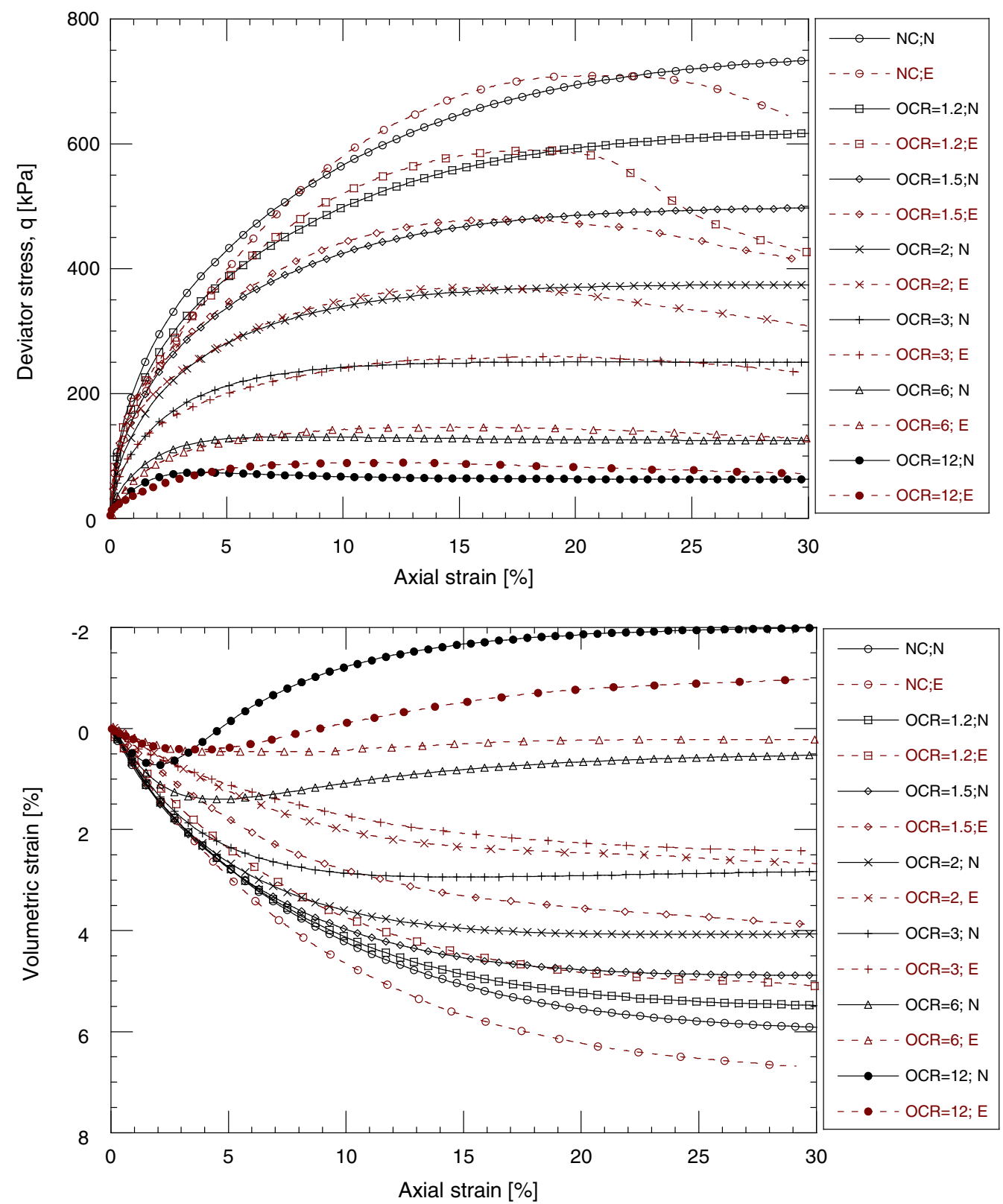

Fig. 19. Comparison between experimental results of drained shear tests at ambient temperature $\left(22^{\circ} \mathrm{C}\right)$ and numerical prediction: E, experimental results [5] and $\mathrm{N}$, numerical results. 
for small strains (elastic domain) of two triaxial tests performed at two different confining pressures and ambient temperature were used. The elastic shear parameter, $G_{\text {ref }}$, was identified plotting the deviatoric stress $\left(\sigma_{1}-\sigma_{3}\right)$ as a function of the deviatoric strain, $2\left(\varepsilon_{1}-\varepsilon_{3}\right)$. The isotropic compression test at ambient temperature was used to get the bulk modulus, $K_{\text {ref, }}$, which corresponds to the slope of the plot relating mean effective stress versus volumetric strain. The non-linear exponent $n$ was determined by combining the values of the parameter $G_{\text {ref }}$ obtained at two different confining pressures.

\subsubsection{Numerical predictions of drained shear tests at} ambient $\left(22^{\circ} \mathrm{C}\right)$ and high temperatures $\left(90^{\circ} \mathrm{C}\right)$

The model's capacity to predict drained shear behaviour at ambient temperature is shown in Fig. 19. It should be noted that drained shear tests in $\mathrm{NC}$ and $\mathrm{OC}$ states $(\mathrm{OCR}=12)$ were used to calibrate the model parameters. Thus, overconsolidated cases (OCR $=1.2,1.5,2.0,3.0$ and 6.0) correspond to the numerical predictions. Comparison between numerical and experimental results in the axial strain-deviator stress plane show good agreement. The only difference appears at large strain for $\mathrm{NC}$ and $\mathrm{OCR}=1.2$ samples. The model predictions of the volumetric strain during shearing are quite satisfactory, in spite of some dispersion between numerical and experimental results.

Comparison between experimental results of drained shear tests at high temperatures, in $\mathrm{NC}$ and $\mathrm{OC}$ states, and numerical predictions is shown in Fig. 20. In the deviatoric plane, model predictions are in accordance with the experimental results for high values of OCR (12, 6 and 3). For NC and lightly overconsolidated samples (1.2, 1.5 and
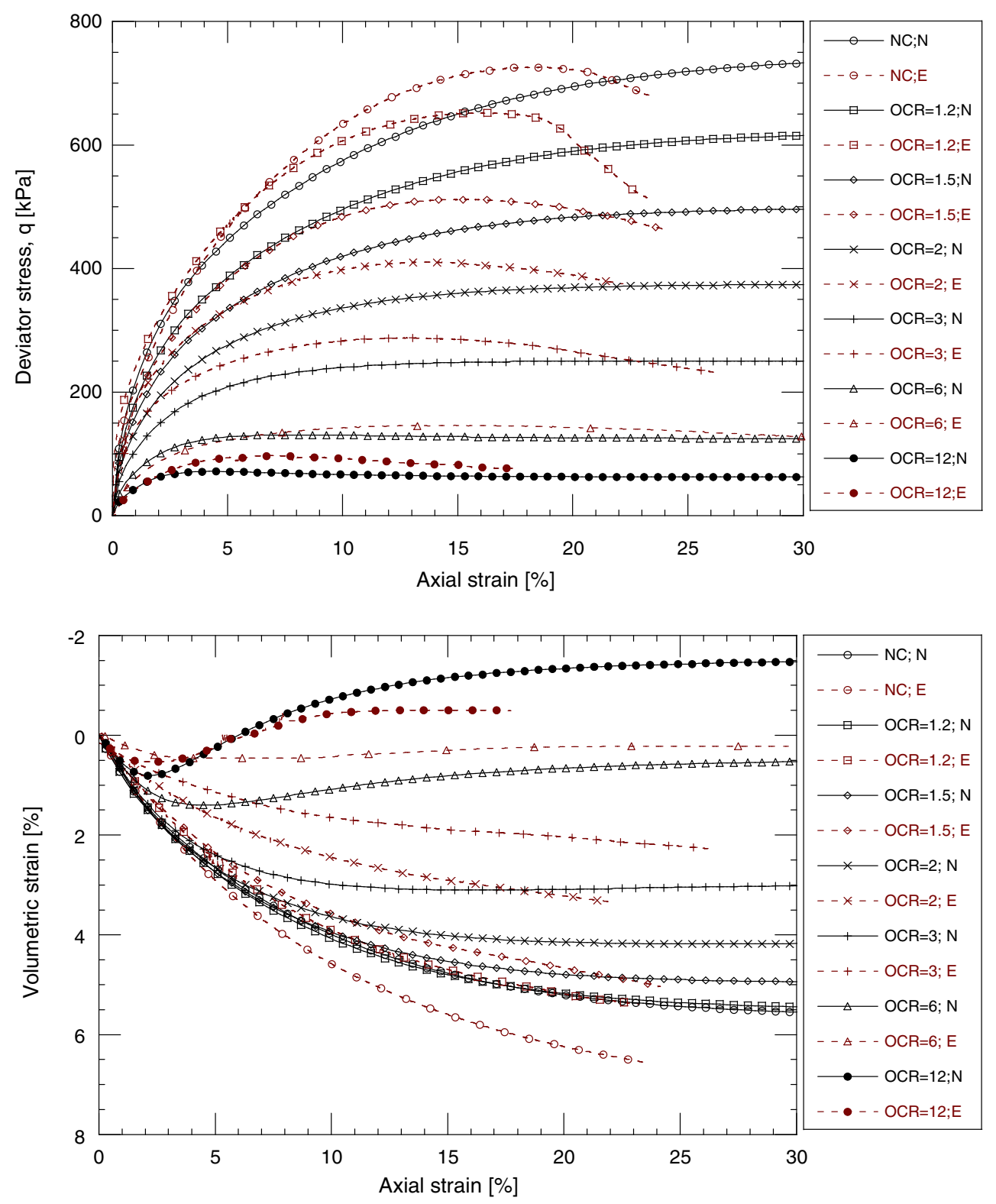

Fig. 20. Comparison between experimental results of drained shear tests and numerical prediction at high temperature $\left(90^{\circ} \mathrm{C}\right)$ : E, experimental results $[5]$ and $\mathrm{N}$, numerical results. 


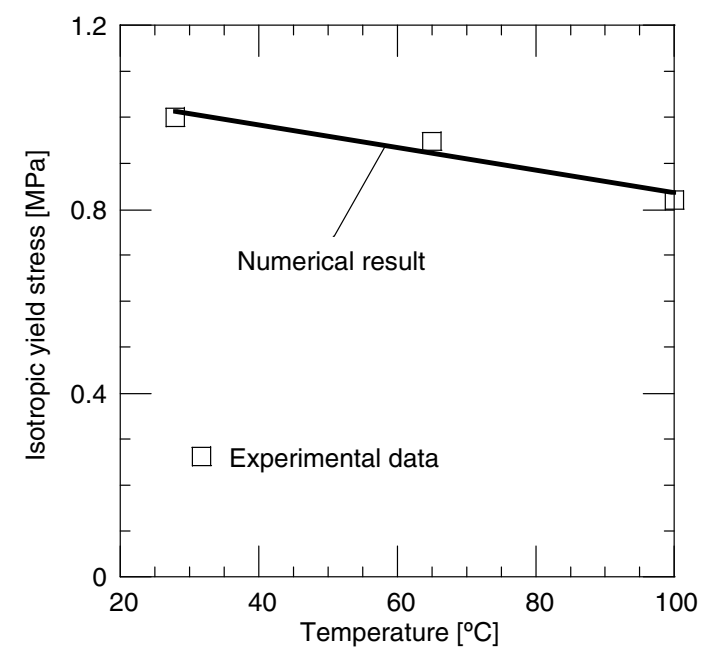

Fig. 21. Comparison between experimental results [8] and numerical back-prediction for the evolution of isotropic yield stress with temperature.

2), the model predicts more ductile behaviour than observed experimentally. As a consequence of thermal densification, the model predicted slightly smaller volumetric strain at high temperature relative to $22^{\circ} \mathrm{C}$.

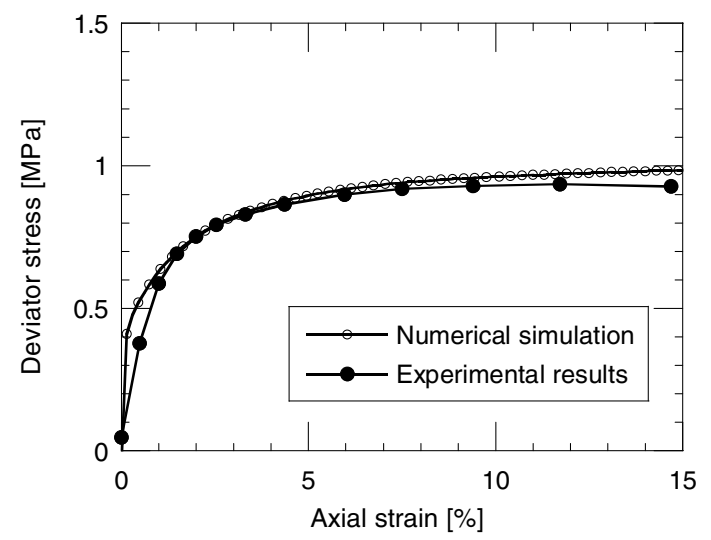

\subsection{Numerical simulation of the behaviour of reconstituted} Illite

Graham et al. [8] reported several isotropic consolidation tests and undrained triaxial shear tests performed at 28, 65 and $100{ }^{\circ} \mathrm{C}$. Tests were performed on specimens of commercially available crushed illitic shale. To prepare specimens, dried powered clay was mixed with distilled water at $1.7 \times w_{\mathrm{L}}$ and consolidated applying step loading. The samples were then obtained by trimming the block samples. The properties of the Illite are provided in Table 2.

An important aim of the research work reported by Graham et al. [8] was to demonstrate how clays behave in undrained, constant-mass conditions. The testing program consisted of two sets of tests conducted on normally consolidated NC and overconsolidated OC samples. The procedure for performing these thermo-mechanical tests is as follows.

\subsubsection{Normally consolidated state}

Normally consolidated specimens were produced by increasing the cell pressure to an isotropic effective consolidation pressure of $1.51 \mathrm{MPa}$. After, two samples were

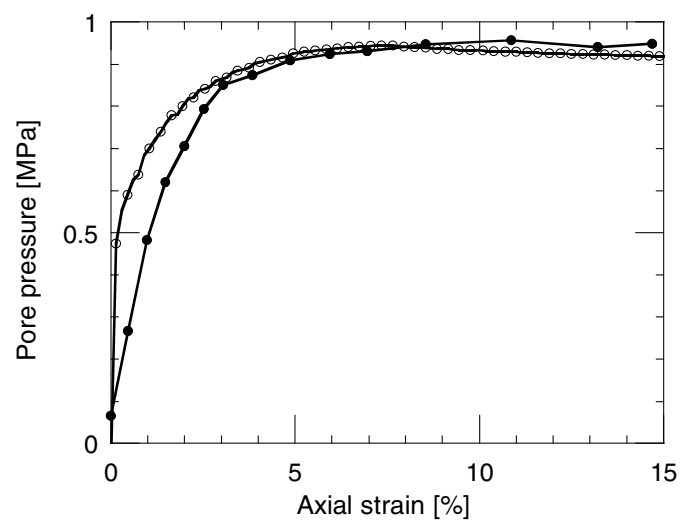

Fig. 22. Undrained shear tests at room temperature in NC state: comparison between experimental results [8] and numerical back-predictions; confining pressure 1.51 MPa.
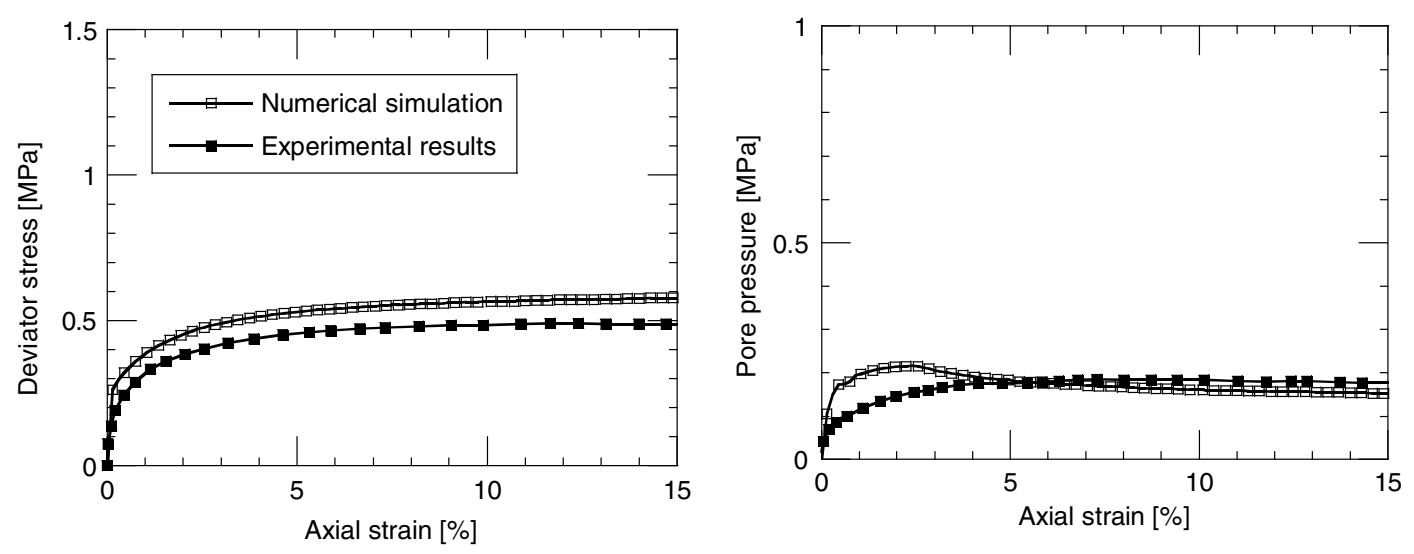

Fig. 23. Undrained shear tests at room temperature in OC state: comparison between experimental results [8] and numerical back-predictions OCR $=2.0$, consolidation pressure $1.0 \mathrm{MPa}$. 
heated: one to $65^{\circ} \mathrm{C}$ and the second to $100{ }^{\circ} \mathrm{C}$ at a heating rate of $6^{\circ} \mathrm{C} / \mathrm{h}$ under drained conditions. Finally, undrained shearing was conducted at three constant temperatures: 28 , 65 and $100{ }^{\circ} \mathrm{C}$.

\subsubsection{Overconsolidated state}

Overconsolidated specimens were produced by applying an effective consolidation pressure up to $1 \mathrm{MPa}$ followed by isotropic unloading to $0.5 \mathrm{MPa}$, giving an $\mathrm{OCR}=2.0$. After, one sample was heated under drained conditions to $65^{\circ} \mathrm{C}$ followed by undrained shearing at this temperature.

To ensure saturation and prevent pore water boiling, back pressures up to $1 \mathrm{MPa}$ were commonly used.

\subsubsection{Calibration of model parameters and back-predictions}

The model parameters of the Illite clay (Table 1) were obtained using the following test: (i) mechanical consolidation test at $28^{\circ} \mathrm{C}$, (ii) isotropic consolidation tests at different temperatures and (iii) two undrained shear tests performed on $\mathrm{NC}$ and $\mathrm{OC}$ samples at $28^{\circ} \mathrm{C}$. The friction angle value at critical state is provided by the authors [8], who also reported that the strength envelope is independent of testing temperature. The evolution of the tangent shear modulus versus shear strain for different stress paths was also given.

The evolution of the isotropic yield stress with temperature is given in Fig. 21. Comparison between experimental results of undrained shear tests and back-predictions are depicted in Figs. 22 and 23.

\subsubsection{Numerical predictions}

Two undrained shear tests at $65^{\circ} \mathrm{C}$ performed on normally consolidated (confining pressure of $1.51 \mathrm{MPa}$ ) and overconsolidated samples $(\mathrm{OCR}=2.0$, consolidation pressure of $1 \mathrm{MPa}$ ) are shown in Fig. 24. The NC sample shows higher deviator stress and pore pressure compared to overconsolidated samples. The measured excess pore pressure of the OC sample remains positive until axial strains larger than $7 \%$.

The undrained shear test performed at $100{ }^{\circ} \mathrm{C}$ on a $\mathrm{NC}$ sample is shown in Fig. 25. The experimental results indicate that pore pressures generated at this temperature are lower than those at $65^{\circ} \mathrm{C}$. However, two tests at high temperature $\left(65\right.$ and $\left.100^{\circ} \mathrm{C}\right)$ show similar results for shear strength.

The numerical predictions compare well with the experimental results in both cases, except for pore pressures gen-
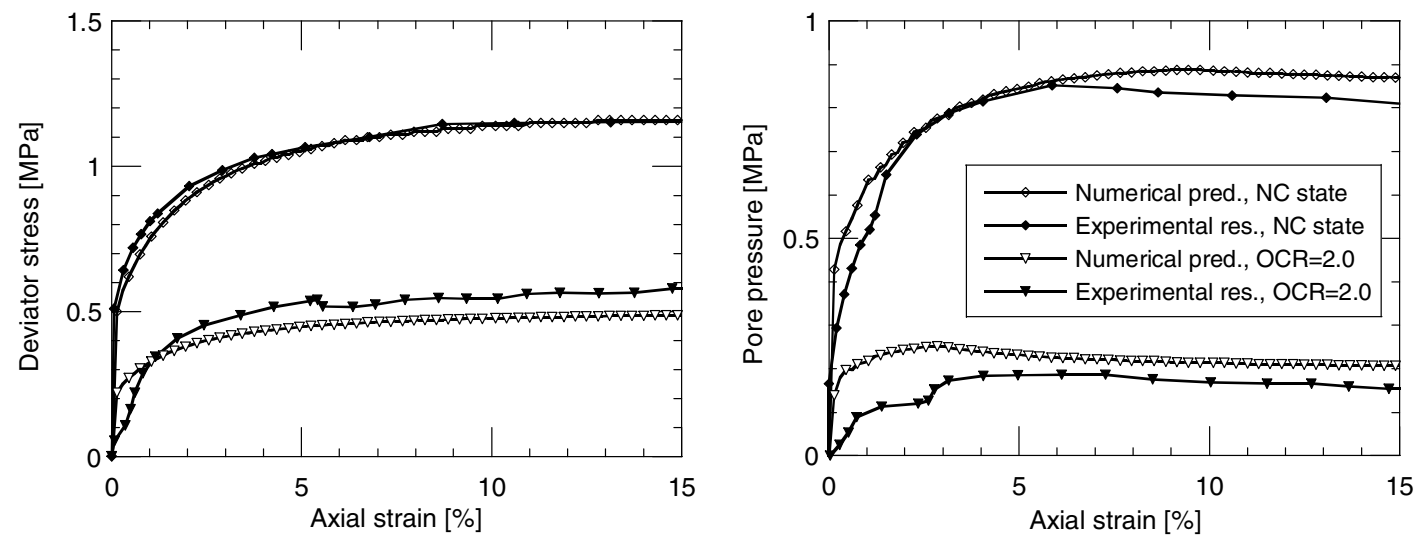

Fig. 24. Comparison between experimental result [8] of undrained shear test and numerical predictions at $65^{\circ} \mathrm{C}(\mathrm{NC}$ and $\mathrm{OC}$ states).
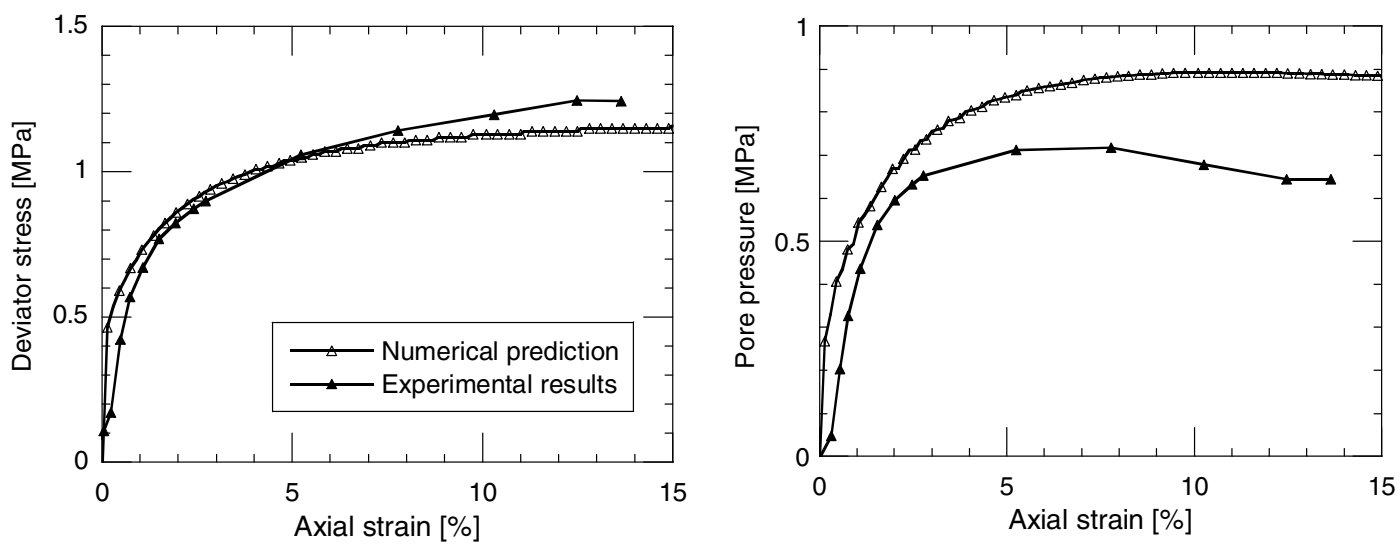

Fig. 25. Comparison between experimental result [8] of undrained shear test and numerical prediction at $100{ }^{\circ} \mathrm{C}(\mathrm{NC}$ state); confining pressure $1.51 \mathrm{MPa}$. 
erated at $100{ }^{\circ} \mathrm{C}$. In this case, the predicted value of pore pressure is slightly higher than the experimentally observed.

\section{Conclusions}

This paper focused on the constitutive modelling of thermo-mechanical behaviour of soils. A non-isothermal mechanical constitutive model was presented. The driving effect is the thermal influence on the void ratio and its consequences on pre-consolidation pressure. This temperatureinduced change in the pre-consolidation pressure was modeled with a dependency law using only one material parameter. The isotropic and the deviatoric behaviours are coupled through the volumetric thermo-plastic strain.

The constitutive model was validated under several thermo-mechanical conditions on four materials. Typical features of the thermo-mechanical behaviour of soils are well reproduced. The numerical predictions clearly indicate that the model is able to predict shear paths in drained, as well as under undrained conditions, at different temperatures. The model captures the effects of stress and temperature histories. Therefore, this constitutive model can be used for the quantitative predictions of the thermomechanical behaviour of cohesive soils.

\section{References}

[1] Baldi G, Hueckel T, Peano A, Pellegrini R. Developments in modelling of thermo-hydro-geomechanical behaviour of Boom clay and clay-based buffer materials. Report EUR 13365, Commission of the European Communities, Nuclear Science and Technology, 1991.

[2] Biot MA. Theory of propagation of elastic waves in fluid-saturated porous solid. J Acoust Soc America 1956;28:168-78.

[3] Boudali M, Leroueil S, Srinivasa Murthy BR. Viscous behaviour of natural clays. In: Proceedings of 13th ICSMFE, New Delhi, No. 1, 1994, p. 411-16.

[4] Cekerevac C. Thermal effects on the mechanical behaviour of saturated soils: an experimental, constitutive and numerical approach. Ph.D. Dissertation no. 2828, EPF Lausanne, 2003, 233 p.

[5] Cekerevac C, Laloui L. Experimental study of thermal effects on the mechanical behaviour of a clay. Int J Numer Anal Meth Geomech 2004;28(3):209-28.
[6] Cui YJ, Sultan N, Delage P. A thermomechanical model for saturated clays. Can Geotech J 2000;37(3):607-20.

[7] Eriksson LG. Temperature effects on consolidation properties of sulphide clays. In: Proceedings of the 12th International Conference on Soil Mechanics and Foundation Engineering, No. 3, 1989, p. 2087-90.

[8] Graham J, Tanaka N, Crilly T, Alfaro M. Modified Cam-clay modelling of temperature effects in clays. Can Geotech $\mathbf{J}$ 2001;38:608-21.

[9] Hueckel T, Borsetto M. Thermoplasticity of saturated soils and shales: constitutive equations. J Geotech Eng 1990;116:1765-77.

[10] Hujeux J-C. Une loi de comportement pour le chargement cyclique des sols. In: Genie Prasismique, Davidovici V, editor. presses de l'ENPC, Paris, 1985, p. 287-353.

[11] Henkel DJ. The correlation between deformation, pore water pressure and strength characteristics of saturated clays. Doctoral thesis, University of London, 1958.

[12] Kuntiwattanakul P. Effect of high temperature on mechanical behaviour of clays. Doctoral thesis, University of Tokyo, 1991.

[13] Kuntiwattanakul P, Towhata I, Ohishi K, Seko I. Temperature effects on undrained shear characteristics of clay. Soils Foundation 1995;35(1):147-62.

[14] Laloui L. Modélisation du comportement thermo-hydro-mécanique des milieux poreux anélastiques. Doctoral thesis, Ecole Centrale Paris, 1993.

[15] Laloui L. Thermo-mechanical behaviour of soils. Revue Française de Génie Civil 2001;5:809-43.

[16] Laloui L, Cekerevac C. Thermo-plasticity of clays: an isotropic yield mechanism. Comput Geotech 2003;30(8):649-60.

[17] Mandel J. Une généralisation de la théorie de Koiter. Int J Solids Struct 1965;1:273-95.

[18] Modaressi H, Laloui L. A thermo-viscoplastic constitutive model for clays. Int J Numer Anal Meth Geomech 1997;21:313-35.

[19] Moritz L. Geotechnical properties of clay at elevated temperatures. Swedish Geotech Inst 1995:69.

[20] Prager W. Non-isothermal plastic deformation, Koninkklijk-Nederland Akademie Van Wetenschappen Te Amsterdam - Proceedings of the Section of Sciences B, 1958, p. 61.

[21] Roscoe KH, Burland IB. On the generalised stress-strain behaviour of wet clay. Eng Plast, Cambridge 1968:535-609.

[22] Roscoe KH, Schofield AN, Wroth CP. On the yielding of soils. Géotechnique 1958;8:22-53.

[23] Tidfors M, Sällfors S. Temperature effect on preconsolidation pressure. Geotech Testing J 1989;12-1:93-7.

[24] Towhata I, Kuntiwattanakul P, Seko I, Ohishi K. Volume change of clays induced by heating as observed in consolidation tests. Soils Foundation 1993;33(4):179-83. 